\title{
Weather Types and Hourly to Multiday Rainfall Characteristics in Tropical Australia
}

\author{
VINCENT MORON \\ Aix Marseille University, CNRS, IRD, INRA, Coll. de France, CEREGE, Aix en Provence, France
}

RENAUD BARBERO

IRSTEA, Mediterranean Ecosystems and Risks, Aix en Provence, France

\author{
JASON P. EVANS
}

Climate Change Research Centre School of Biological, Earth and Environmental Sciences, University of New South Wales, Sydney, New South Wales, Australia

SETH WESTRA

Faculty of Engineering, Computer and Mathematical Sciences, University of Adelaide, Adelaide, South Australia, Australia

HAYLEY J. FOWLER

School of Engineering, Newcastle University, Newcastle upon Tyne, United Kingdom

(Manuscript received 26 June 2018, in final form 25 March 2019)

\begin{abstract}
Six weather types (WTs) are computed for tropical Australia during the wet season (November-March 1979-2015) using cluster analysis of 6-hourly low-level winds at $850 \mathrm{hPa}$. The WTs may be interpreted as a varying combination of at least five distinct phenomena operating at different time scales: the diurnal cycle, fast and recurrent atmospheric phenomena such as transient low pressure, the intraseasonal Madden-Julian oscillation, the annual cycle, and interannual variations mostly associated with El Niño-Southern Oscillation. The WTs are also strongly phase-locked onto the break/active phases of the monsoon; two WTs characterize mostly the trade-wind regime prevalent either at the start and the end of the monsoon or during its breaks, while three monsoonal WTs occur mostly during its core and active phases. The WT influence is strongest for the frequency of wet spells, while the influence on intensity varies according to the temporal aggregation of the rainfall. At hourly time scale, the climatological mean wet intensity tends to be near-constant in space and not systematically larger for the monsoonal WTs compared to other WTs. Nevertheless, one transitional WT, most prevalent around late November and characterized by weak synoptic forcings and overall drier conditions than the monsoonal WTs, is associated with an increased number of high hourly rainfall intensities for some stations, including for the interior of the Cape York Peninsula. When the temporal aggregation exceeds 6-12 h, the mean intensity tends to be larger for some of the monsoonal WTs, in association with more frequent and also slightly longer wet spells.
\end{abstract}

\section{Introduction}

Tropical rains are mostly convective and usually fall as short and intense events, lasting a few minutes to a few hours, and occurring generally between midafternoon and early night in response to the diurnal cycle of solar radiation and boundary forcing (Ricciardulli and Sardeshmukh 2002; Slingo et al. 2003). The rain-bearing

\footnotetext{
Corresponding author: Vincent Moron, moron@cerege.fr
}

systems may be isolated cumulonimbus and thunderstorms as well as larger phenomena such as mesoscale convective clusters or tropical depressions, including tropical cyclones. The storm duration mostly depends on the spatial extent of the triggering systems, their traveling speed and the amount of moisture available. Favorable combinations may lead to rainfall extremes, responsible for flash flooding with potentially significant consequences on lives, infrastructure, and natural ecosystems. 
There has been much interest in recent years in rainfall extremes due to their potential intensification in the future under a warming climate, including across tropical Australia (Bao et al. 2017). The local-scale rainfall may be decomposed into different, but related, characteristics which belong to three broad families: (i) the frequency or occurrence of wet conditions, that is, a simple look at the rain as a binary variable, dry or wet, the only parameter being the threshold used to define the wetness; (ii) the duration of wet conditions; and (iii) the intensity, defined either as the instantaneous rate or the amount received during a fixed period of time. These characteristics are indeed statistically related since, for a given amount, the shorter the storm, the higher the intensity (Dai et al. 2017). As a first-order approximation, convective rainfall is generally thought to be short (minutes to hours) and intense. Most studies based on daily data fail to capture the actual intensity as both moderate but long-lasting rainfall and short but intense rainfall may contribute equally to daily precipitation depth. These subdaily features are obviously lost in daily measurements. Moreover, hourly data may enable a more stringent separation of the true intensity (even if rain rate may strongly vary under a convective cell at subhourly time scales) and the duration of wet events (Trenberth et al. 2017).

Observational evidence suggests that rainfall extremes on subdaily time scales may increase faster than expected in a warmer climate due to local thermodynamical factors (Lenderink et al. 2017). Previous studies using hourly rainfall data in tropical Australia have thus focused mainly on the thermodynamic effects of local temperature or dewpoint temperature (Hardwick Jones et al. 2010; Wasko et al. 2015; Barbero et al. 2018) and the broader impacts of global warming (Guerreiro et al. 2018) with the aim of providing a better understanding of future changes to short-duration rainfall extremes in a warmer climate (Westra et al. 2014). However, largescale circulation may also amplify or dampen regional thermodynamic forcing (Pfahl et al. 2017), by inducing local changes in both temperature and moisture or by modulating the degree of mesoscale organization (Lochbihler et al. 2017). Recent findings indicate that subdaily rainfall extremes are often associated with large-scale systems (Luo et al. 2016; Utsumi et al. 2017; Loriaux et al. 2017; Barbero et al. 2019) and both thermodynamical and dynamical factors have been shown to contribute to the occurrence of precipitation extremes (Ali and Mishra 2018). It is thus of interest to examine how regional-scale atmospheric circulation influences rainfall characteristics, including frequency, duration, and intensity across a range of time scales, to better understand drivers and processes.
Atmospheric circulation is analyzed here through recurrent regional-scale patterns referred to as weather types (WTs). WTs have been employed extensively to diagnose and describe atmospheric patterns in the extratropical zone, especially in winter at hemispheric and regional scales (Ghil and Robertson 2002; Michelangeli et al. 1995; Agel et al. 2015) and are usually defined based on sea level pressure or geopotential height in the midtroposphere levels. This approach has also been used in the tropical zone at regional scales (Pohl et al. 2005; Moron et al. 2008, 2015a) where WTs are usually defined using low-level $(925$ or $850 \mathrm{hPa}$ ) winds to capture the intensity of the monsoonal and trade-wind regimes, and/or outgoing longwave radiation to capture deep convection. The WTs allow consideration of the whole spectrum of variance, and, contrary to any space-time filtering, they usually combine different phenomena and time scales that have similar fingerprints and are thus associated with a given WT. The WT approach is comprehensive in the sense that it does not consider any subjective selection of bandwidths and thus includes all recurrent phenomena, from synoptic events with similar tracks to phases of coupled-convective equatorial waves such as Madden-Julian oscillation (MJO). This approach may however be more difficult to interpret due to this superposition of different phenomena and time scales, beyond the fact that a WT (as specific bandwidths) discretizes a continuum.

We present here results of weather typing across a domain centered over tropical Australia north of $25^{\circ} \mathrm{S}$, delineated as monsoonal. The region experiences a short wet season characterized by low-level westerlies associated with the proximity of the active equatorial trough from December to February (Troup 1961; Suppiah 1992; McBride 1987; Drosdowsky 1996; Wheeler and McBride 2005), while a prolonged dry season during the rest of the year is related to the influence of the subtropical ridge and southeast trade winds. We interpret the multiWT picture as a multiscale interactions of atmospheric motions from 6-hourly to the interannual time scale. This is done by considering a priori explicitly a range of forcings operating at different time scales [the diurnal and seasonal cycles, the phases of the MJO, and the states of El Niño-Southern Oscillation (ENSO)] which have been recognized as significant drivers of intraseasonal and interannual variations of Australian rainfall (McBride and Nicholls 1983; Risbey et al. 2009; Pui et al. 2012; Wheeler and McBride 2005; King et al. 2014). We then analyze the relationships between WTs and rainfall frequency, duration and intensity from hourly to multiday time scales through a cross-scale analysis.

The paper is organized as follows. In section 2, we describe the data used and the $k$-means clustering 
method that generates the WTs. We detail the preprocessing used to compare the 6-hourly WTs and hourly rainfall as well as the definitions of the three rainfall characteristics examined. Section 3 details the mean rainfall patterns. Section 4 details each resulting WT pattern in terms of raw and anomalous $850 \mathrm{hPa}$ winds, and analyzes their relation to the diurnal and seasonal cycles, interannual ENSO events and intraseasonal MJO phases. Last, section 5 evaluates the WTs' influence on regional- and local-scale rainfall. In section 6, we summarize and discuss our results.

\section{Data and methods}

\section{a. Low-level winds and definition of atmospheric weather types}

The $850 \mathrm{hPa}$ winds are extracted from ERA-Interim at the 6-hourly time scale and a horizontal resolution of $2^{\circ}$ from 1979 to 2016 , covering 37 full wet seasons from 1 November to 31 March. Note that using the highest resolution of $0.75^{\circ}$ is unnecessary as WTs focus on recurrent patterns at synoptic-to-regional scales and an EOF analysis is used to prefilter the smallest scales. Four reanalyses per day at 0000, 0600, 1200, and 1800 UTC are extracted on 1 November-31 March to focus on the austral monsoon only.

The WTs are defined from a well-known dynamical clustering algorithm ( $k$ means), which has been extensively used in previous studies (Michelangeli et al. 1995; Christiansen 2007; Moron et al. 2015a; Roller et al. 2016). Only a short summary is given here. Note that we do not use clustering to define the hypothetical weather regimes, which are topological attractors of the phase space of atmospheric motions, as this type of clustering appears to be particularly fragile (Christiansen 2007). Our goal is simply to use the clustering as a dataadaptive filter of atmospheric circulation; that is, discretizing the complex low-level atmospheric circulation into a finite number of typical patterns (the WTs). The zonal and meridional components of the $850 \mathrm{hPa}$ winds are normalized using the overall pointwise mean and standard deviation to consider all variations from the 6hourly time scale, including the seasonal cycle. The anomalies of the zonal and meridional components of the $850 \mathrm{hPa}$ winds are then projected onto the leading 25 principal components (PCs) that collectively account for $75 \%$ of the total variance. The $k$-means algorithm is then applied to the leading 25 PCs using Euclidean distance to measure the distances between each observation and the centroids of the clusters. 1000 replicates are made from different random seeds for each value of $k$ ranging from 2 to 10 , and the solution showing the largest average similarity (between one solution and the 999 remaining ones) is considered as the final clustering for any value of $k$. The similarity is estimated with the classifiability index (CI) (Michelangeli et al. 1995; Roller et al. 2016), which equals 1 if the centroids are fully insensitive to the random seeds, that is, if all 1000 partitions starting from different initial seeds are identical. The "optimal" number of clusters $k$ is defined by comparing the observed CI with 100 simulations using rednoise processes having the same variance and first-order autocorrelation as the observed PCs. The solution of $k=$ 6 clusters was found to be significant at the one-sided $95 \%$ level (not shown) and was considered in the following analysis.

To test the sensitivity of the WTs to the choice of reanalyses, we extracted the ERA5 database on the common available period from 1 January 2000 to 31 March 2016. The centroids of the six clusters used in the paper were then computed from ERA-Interim on the season 1 November-31 March 2000-16 and the standardized anomalies (with respect to the long-term 1 November-31 March climatological mean) from ERA5 were clustered on these centroids using the Euclidean distance. We found that $90.6 \%$ of the ERA5 slots belong to the same cluster as defined originally through ERA-Interim on a longer period. Based on this cross analysis, we conclude that the six clusters analyzed below are robust and insensitive to the choice of reanalyses.

The WTs were also compared with two other estimates of the regional-scale monsoon, namely, the weather regimes (Pope et al. 2009; Catto et al. 2012) and the sequences of break/active phases and the onset/ demise (Hung and Yanai 2004) of the regional-scale monsoon.

\section{b. Weather regimes at Darwin}

The weather regimes (WR) (Pope et al. 2009; Catto et al. 2012) defined from the 0830 LST radio soundings at Darwin provide the opportunity to compare our regional-scale WTs (from the 0000 UTC slot) based on the wind at a single level with five WRs defined from the vertical atmospheric structure (temperature, zonal, and meridional components of the wind at 16 levels from the surface to $100 \mathrm{hPa}$ ) observed at a single station (i.e., Darwin) located close to the geographical center of the WTs domain. A close resemblance, if any, would suggest that the local-scale atmospheric vertical structure and the regional-scale atmospheric pattern may be interpreted as different, but complementary, point of views of the same atmospheric state. The local-scale approach (i.e., WRs) focuses on the precise thermodynamical processes acting locally while the regional-scale 
TABLE 1. Conditional frequencies between weather types (WT) and the weather regimes from Pope et al. (2009). The values are expressed as anomalous frequencies (vs expected frequencies in percentage) and the bold values are significant at the two-sided $95 \%$ level according to a random permutation (1000 times) of the WT time series by season, such as the mean seasonal cycle is kept in the reshuffled sequences.

\begin{tabular}{lcccrr}
\hline & R1 dry east regime & R2 deep west regime & R3 east regime & R4 shallow west regime & R5 moist east regime \\
\hline WT 1 & $\mathbf{+ 6 7}$ & $\mathbf{- 9 4}$ & $\mathbf{+ 1 6 2}$ & $\mathbf{- 7 2}$ & $\mathbf{+ 1 2}$ \\
WT 2 & -18 & -32 & $\mathbf{- 4 3}$ & $\mathbf{+ 4 6}$ & $\mathbf{+ 3}$ \\
WT 3 & $\mathbf{- 6 7}$ & +17 & $\mathbf{- 6 7}$ & $\mathbf{- 4 8}$ & $\mathbf{+ 5 2}$ \\
WT 4 & -47 & $\mathbf{+ 2 7 2}$ & $\mathbf{- 9 8}$ & $\mathbf{+ 5 3}$ & $\mathbf{- 6 3}$ \\
WT 5 & -5 & $\mathbf{- 1 0}$ & $\mathbf{- 8 5}$ & -2 & $\mathbf{- 4 8}$ \\
WT 6 & +36 & $\mathbf{- 7 0}$ & $\mathbf{+ 2 5}$ & +14 \\
\hline
\end{tabular}

approach (i.e., WTs) focuses on recurrent atmospheric patterns, regardless of small-scale details.

\section{c. Break/active phases and onset/demise of the regional-scale Australian monsoon}

The WTs are also compared with the sequences of break and active phases of the regional-scale monsoon (Troup 1961), defined using a wind and a rainfall index. The wind index is the spatial average of the zonal component of the $850 \mathrm{hPa}$ wind from ERA-Interim across the Arafura Sea and northern Australia ( $1^{\circ}-$ $\left.15^{\circ} \mathrm{S}, 115^{\circ}-151^{\circ} \mathrm{E}\right)$ and has been used by Hung and Yanai (2004) to define the regional-scale monsoon onset over Australia. The rainfall index is defined using the spatial average of the gridded $\left(0.05^{\circ} \times 0.05^{\circ}\right)$ Australian Water Availability Project (AWAP) (Jones et al. 2009) daily rainfall north of $25^{\circ} \mathrm{S}$ (H. Hendon 2018, personal communication). Both indices are processed in the same way following Narsey et al. (2017). First, the climatology for the mean and standard deviation are calculated for each day. These climatologies are then smoothed using a low-pass filter that only retains signals with periods longer than 60 days. Active and break periods are respectively defined using the smoothed seasonal cycle, plus and minus half a smoothed standard deviation. Neutral conditions are defined when the index is between minus 0.5 and plus 0.5 standard deviations versus the climatological mean. Note that the AWAP daily accumulated rainfall ends at 0900 LST (central zone). So each daily rainfall is simply duplicated 4 times and compared to the WT occurring from 0000 to 1800 UTC the day before. This approach assumes a 3-h delay between rainfall and WT and fully overlooks the diurnal cycle of rainfall. The comparison between a wind and a rainfall index is interesting since break and active phases are defined from different point of views and WTs include (do not include) the wind (rainfall) information. In fact, only $51 \%$ of 6 -hourly slots fall simultaneously in one of the three categories defined from wind and rainfall, but only $9 \%$ are categorized in an opposite phase (active versus break and break versus active). Last, the wind index is used to define a regional-scale onset and demise of the monsoon: the onset (demise) is defined as the first (last) 6-h slot with zonal wind above $2 \mathrm{~m} \mathrm{~s}^{-1}$ with at least 10 consecutive days thereafter (before). The mean onset date occurs on 29 December [standard deviation (sd) $=18$ days], close to previous estimates of 25 December (sd = 14-16 days) (Hung and Yanai 2004; Hendon and Liebmann 1990). The mean demise date occurs on 11 March (sd = 11 days).

The co-occurrence of WTs with both WRs and the three phases of the regional-scale monsoon is analyzed through contingency tables. The conditional frequencies (expressed as anomalies versus the expected frequencies estimated from the cross product of the marginal frequencies divided by the total number of observations) between WTs and both WRs and active/neutral/break phases are displayed in Tables 1 and 2. The dependency of the onset and demise of the regional-scale monsoon is estimated through the relative frequency of the 6 WTs over a period spanning from 10 days before to 10 days after the onset and demise (Fig. 5).

TABLE 2. Conditional frequencies between weather types (WT) and the break, neutral, and active phases of the regional-scale monsoon defined from a rainfall (first value of each cell) and a wind (second value of each cell) index. The values are expressed as anomalous frequencies (vs expected frequencies in percentage) and the bold values are significant at the two-sided $95 \%$ level according to a random permutation (1000 times) of the WT time series by season, such as the mean seasonal cycle is kept in the reshuffled sequences.

\begin{tabular}{|c|c|c|c|}
\hline & Active & Neutral & Break \\
\hline WT 1 & $-64 /-88$ & $+1 /-26$ & $+44 /+109$ \\
\hline WT 2 & $-8 /+9$ & $+22 /+28$ & $-14 /-39$ \\
\hline WT 3 & $+36 /-49$ & $+13 /+25$ & $\mathbf{- 3 7 / + 1 8}$ \\
\hline WT 4 & $+146 /+138$ & $-24 /-26$ & $-81 /-98$ \\
\hline WT 5 & $+7 /+\mathbf{1 2 1}$ & $\mathbf{+ 1 2} /-13$ & $-15 /-97$ \\
\hline WT 6 & $-57 /-48$ & $-25 /+15$ & $+63 /+28$ \\
\hline
\end{tabular}




\section{d. Cyclonic events around tropical Australia}

WTs, by definition, filter out the smallest scales and nonrecurrent atmospheric phenomena. Nevertheless, this does not mean that WTs are unable to capture synoptic-scale features. We used a cyclone database (http://www.bom.gov.au/cyclone/history/index.shtml) providing the longitude, latitude, and dates of past cyclone events in tropical Australia. A total of 8911 cyclonic centers were detected within the WTs domain over the whole analyzed period. The location of the 8911 cyclonic centers is mapped during each WT (see Fig. A4).

\section{e. Weather types across the Maritime Continent}

The Australian monsoon belongs to a broader monsoonal system encompassing the whole of the Maritime Continent (MC), from Indonesia to New Guinea, tropical Australia, and the western tropical Pacific Ocean (McBride 1987; Wheeler and McBride 2005). Moron et al. (2015a) defined six weather types over the MC $\left(15^{\circ} \mathrm{S}-15^{\circ} \mathrm{N}, 90^{\circ}-150^{\circ} \mathrm{E}\right)$ from the daily zonal and meridional component of the $850 \mathrm{hPa}$ wind (from NCEP-DOE reanalyses) from 1979 to 2013 (1 September-30 April). Two WTs (WT1 and WT6) characterize the regional-scale atmospheric circulation before and after the core of the monsoon season across MC with trade winds over northern Australia and adjacent seas. WT2 is a transitional WT between the dry and wet season while WTs 3 and 4 reflect the core of the wet season with westerlies over the whole area north of $10^{\circ}-15^{\circ} \mathrm{S}$. WT5 also occurs mostly during the core of the wet season but is associated with anomalously "quiescent" winds leading to a smallscale contrast of rainfall across the Indonesian islands, partly due to an enhanced diurnal cycle which counteracts the regional-scale effect of the weak monsoonal flow (Qian et al. 2010, 2013). The time series of the MC WTs has been updated until March 2016 from daily NCEP-DOE reanalyses used in Moron et al. (2015a) and replicated to the 6-hourly time scale to be compared with the six Australian WTs. As before, the dependency between both sets of WT is analyzed through contingency tables (see Table 4).

\section{f. Daily rainfall from GPCP}

The gridded daily rainfall are extracted from GPCP v1.3 at $1^{\circ}$ resolution from 1 November to 31 March over the 1996-2016 period and across the whole WT domain. The GPCP data blend various satellites estimates with rain gauges. We use the GPCP to estimate rainfall anomalies at the daily time scale for each WT (Huffman et al. 2001, 2009).

\section{g. El Niño-Southern Oscillation and Madden-Julian oscillation}

We analyze the dependency of WTs on the most important modes of variability at interannual (ENSO) and intraseasonal (MJO) scales. The ENSO state is defined as the seasonal average of the Niño 3.4 (N34) box in December-February (DJF). The frequency of the WTs in 11-day running windows is analyzed for the eight coldest (La Niña) and warmest (El Niño) seasons from N34 in DJF. The significance of the anomalies (with respect to the long-term mean seasonal frequency of the WTs) is estimated by sampling randomly eight seasons (out of 37) 1000 times and comparing the anomalies in this randomized set to the La Niña and El Niño samples. This analysis illustrates the potential slow (i.e., interannual) forcing of ENSO on WTs, but also its possible seasonal modulation.

We next analyze the dependency of WTs on the MJO phases defined by Wheeler and Hendon (2004). The MJO is classified into eight phases (plus a neutral phase) identified through the location of the main anomalous convective center. As for WRs and phases of the regional-scale monsoon, the dependency of the WTs is calculated using contingency tables and the significance of each cell is estimated through 1000 random reshufflings of the seasonal sequences of WTs so that their mean seasonal occurrence is preserved.

\section{h. Processing of the hourly rainfall from rain gauges}

Hourly station-based data are extracted from the Australian database (Guerreiro et al. 2018). All hourly data classified as suspect according to preexisting flags were treated as missing. We selected 61 rain gauges having at least 20 years of available data over the period 1979-2014, covering 35 full seasons from 1 November to 31 March. There is no attempt to fill in the missing entries and all computations below consider only available entries. Hourly measurements were aggregated up to 3 , $6,12,24,48,72,96$, and $120 \mathrm{~h}$ using fixed intervals (e.g., 0000-0300, 0300-0600, . . for 3-h data; 0000-0600, 0600$12000, \ldots$ for 6 -h data and so on). When hourly rainfall is summed over consecutive time steps, any missing entries make the sum missing as well. At the hourly time scale, there are $20.5 \%$ of missing entries on average over the season 1 November-31 March (sd across the 61 stations $=12 \%)$.

\section{i. Weather types and local rainfall anomalies}

To analyze the relationships between each WT and hourly rainfall, the WTs are first replicated on the $6 \mathrm{~h}$ centered on each ERA-Interim time step, that is, the WT observed at 0000 UTC 1 November 1979 is 
replicated 6 times from 2100-2200 UTC 31 October 1979 to 0200-0300 UTC 1 November 1979. Then, we shifted the hourly rainfall record respectively by $8 \mathrm{~h}$ [for 9 rain gauges from Western Australia (WA)], $9 \mathrm{~h}$ [for 8 rain gauges from the Northern Territory (NT)], and $10 \mathrm{~h}$ [for 44 rain gauges from Queensland (QU)] due to the time difference between ERA-Interim and the local standard time in Australia. For example, the WT observed from 2100-2200 UTC 31 October 1979 to 02000300 UTC 1 November 1979 is associated with the 6-h rainfall observed from 1 November 1979 at 0500-0600 LST (WA), 0600-0700 LST (NT), and 0700-0800 LST (QU). Note that there is a slight delay for the Northern Territory, where local time is UTC +0930 . We assume that a WT may persist for at least 6 consecutive hours, given that atmospheric synoptic conditions are generally autocorrelated over longer time scales due to their large spatial scale. Indeed, $95 \%$ and $89 \%$ of 6 -hourly WTs belong to a spell lasting respectively $\geq 12$ and 24 consecutive hours.

The relative frequency of wet events is defined as the fraction of wet hours receiving $\geq 0.2 \mathrm{~mm}$. Similar results are observed when using a threshold of $\geq 1 \mathrm{~mm}$ (not shown). The threshold of $0.2 \mathrm{~mm}$ corresponds to the finest resolution of measurement without inhomogeneities across the rain gauges, as demonstrated by Fig. A1 in the appendix. This threshold has therefore been used to define wet hours in the following analyses to avoid inhomogeneities in the resolution of measurement across space and time that would introduce a bias in the estimated frequency and duration of wet events.

Three rainfall characteristics are computed from hourly records:

1) The frequency of wet and dry hours using the threshold of $0.2 \mathrm{~mm}$, that is, an hour is defined as wet as soon as it receives $\geq 0.2 \mathrm{~mm}$.

2) The duration of wet spells, estimated as the length of consecutive wet hours using the $0.2 \mathrm{~mm}$ threshold. We do not allow for dry hours within wet spells. Our goal is just to compare the duration of wet events using a consistent framework among the WTs. We divided the duration into four classes: very short (1$2 \mathrm{~h}$ ), short (3-6h), medium (7-10h), and long $(\gg 10 \mathrm{~h})$ wet events. Note that the use of an hourly data may slightly bias the duration and intensity of rainfall events, due to intrahourly rainfall variations (Dunkerley 2019).

3) The intensity, computed from the deciles as well as the 95th and 99th percentiles of rainfall depth across various intervals of measurement ranging from 1 to $120 \mathrm{~h}$. Note that the intervals of measurement are fixed and the inclusion of dry hours between two intervals is expected to reduce the actual intensity. The rainfall amounts are categorized into deciles of wet sequences receiving $\geq 0.2 \times L \mathrm{~mm}$, where $L$ is the length of the aggregated period in hours (e.g., a 5-day sequence is defined as wet if receiving $\geq 24 \mathrm{~mm}$ ). The computations are repeated with a fixed threshold $\geq 0.2$ and $\geq 1 \mathrm{~mm}$ independently on the duration of the aggregated period and lead to very similar results (not shown).

The dependency between the above rainfall characteristics and each WT is estimated through contingency tables of bivariate frequencies. The contingency is computed independently on each of the 61 stations, and the individual estimates are then spatially averaged. The spatial average is weighted by the mean distance between one station and the remaining 60 ones, so that less weight is given to the most densely monitored areas such as the east coast of Queensland around Townsville and Cairns (Fig. 1). For each rainfall characteristic, the observed frequencies of events are referred as to $n_{i j}$. The index $i$ indicates different categories of rainfall, from 1 (dry) to 2 (wet) for frequency of wet hours, from 1 (less than a percentile) to 2 (above or equal to a percentile) for the 95th and 99th percentiles of 1-120 h amounts, from 1 to 4 for the classes of duration defined above, and from 1 to 10 for the deciles of $1-120 \mathrm{~h}$ amounts. The index $j$ varies from 1 to 6 for the WTs. For example, $n_{i j}$ may refer to the hourly time steps belonging to the one of the 10 deciles of wet steps receiving at least $0.2 \mathrm{~mm}$ contingent on $\mathrm{WT}_{j}$, and are compared to the expected frequencies $E\left(n_{i j}\right)$. The expected frequency for each bivariate cell equals the product of the marginal frequencies across the WTs $\left(n_{i .}\right)$ and the deciles $\left(n_{. j}\right)$ divided by the total number of available entries $(N)$ in the hourly rainfall record at each rain gauge, $E\left(n_{i j}\right)=n_{. j} \times$ $n_{i} / N$. The anomalous frequency $\left(n_{i j}^{\prime}\right)$ is computed as $n_{i j}^{\prime}=\left\{\left[n_{i j}-E\left(n_{i j}\right)\right] / E\left(n_{i j}\right)\right\} \times 100$ and expressed as percent of anomaly with respect to $E\left(n_{i j}\right)$.

To test the significance of anomalies, we randomly permute blocks of 3 days within sequences of 15 consecutive days across the 35 seasons of WTs and recompute the same anomalies with the original sequences of hourly rainfall (and 6-hourly components of the winds and daily GPCP rainfall). We repeat this 1000 times and compute the 2.5 th and 97.5 th percentile corresponding to a two-sided $95 \%$ level of significance to form an envelope of confidence. By doing this, we test the significance of the deseasonalized anomalies. In other words, we seek to test whether a given WT significantly increases (or decreases) the occurrence of the upper decile of hourly rainfall, or 

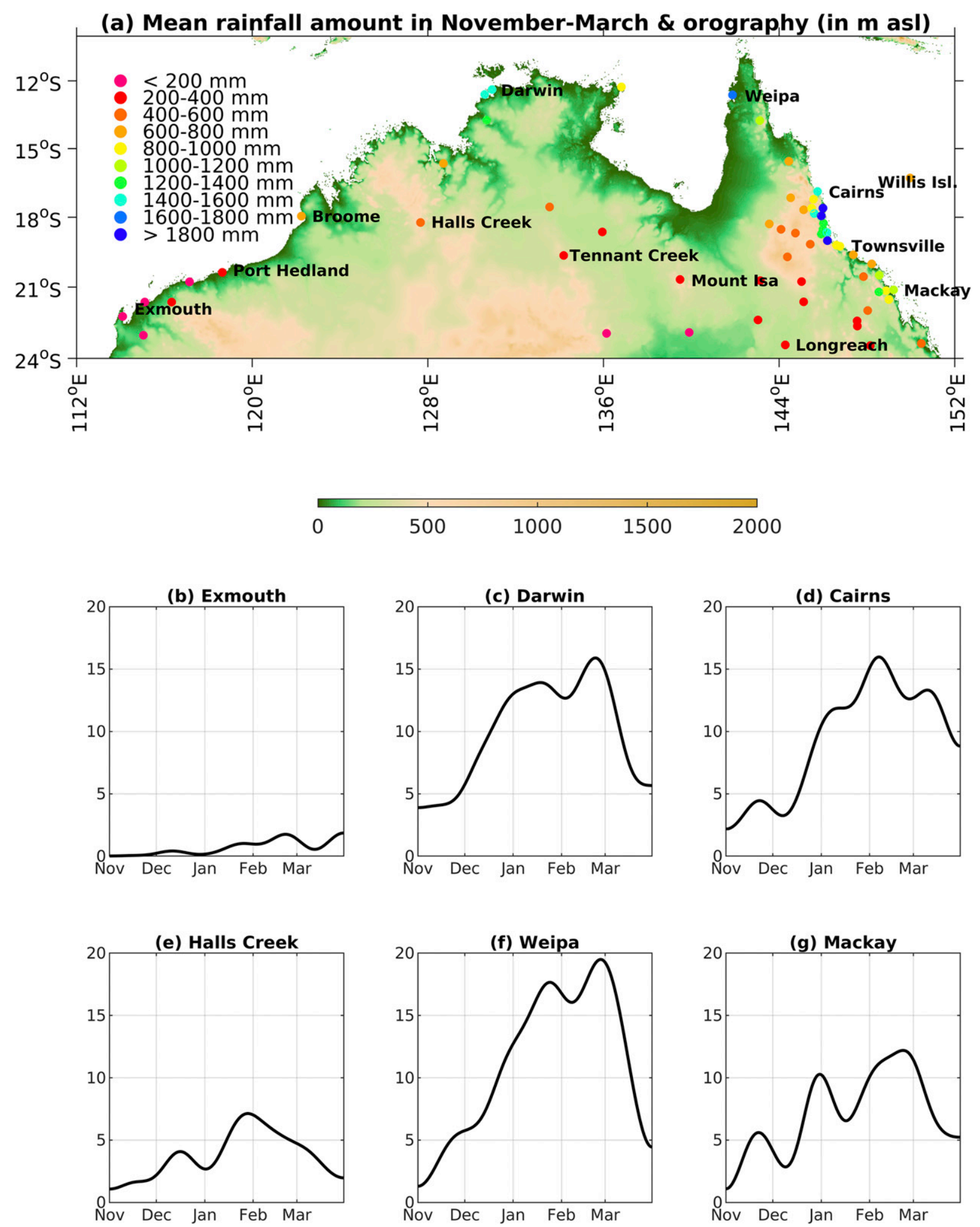

FIG. 1. (a) Orography (shadings) and mean November-March total rainfall in millimeters (dots) recorded at the 61 stations. The mean rainfall is computed using all available entries. (b)-(g) Mean daily rainfall (in mm day ${ }^{-1}$ ) observed at six rain gauges. The climatological daily mean is low-pass filtered with a recursive Butterworth filter with a cutoff at $1 / 30 \mathrm{cpd}$. 

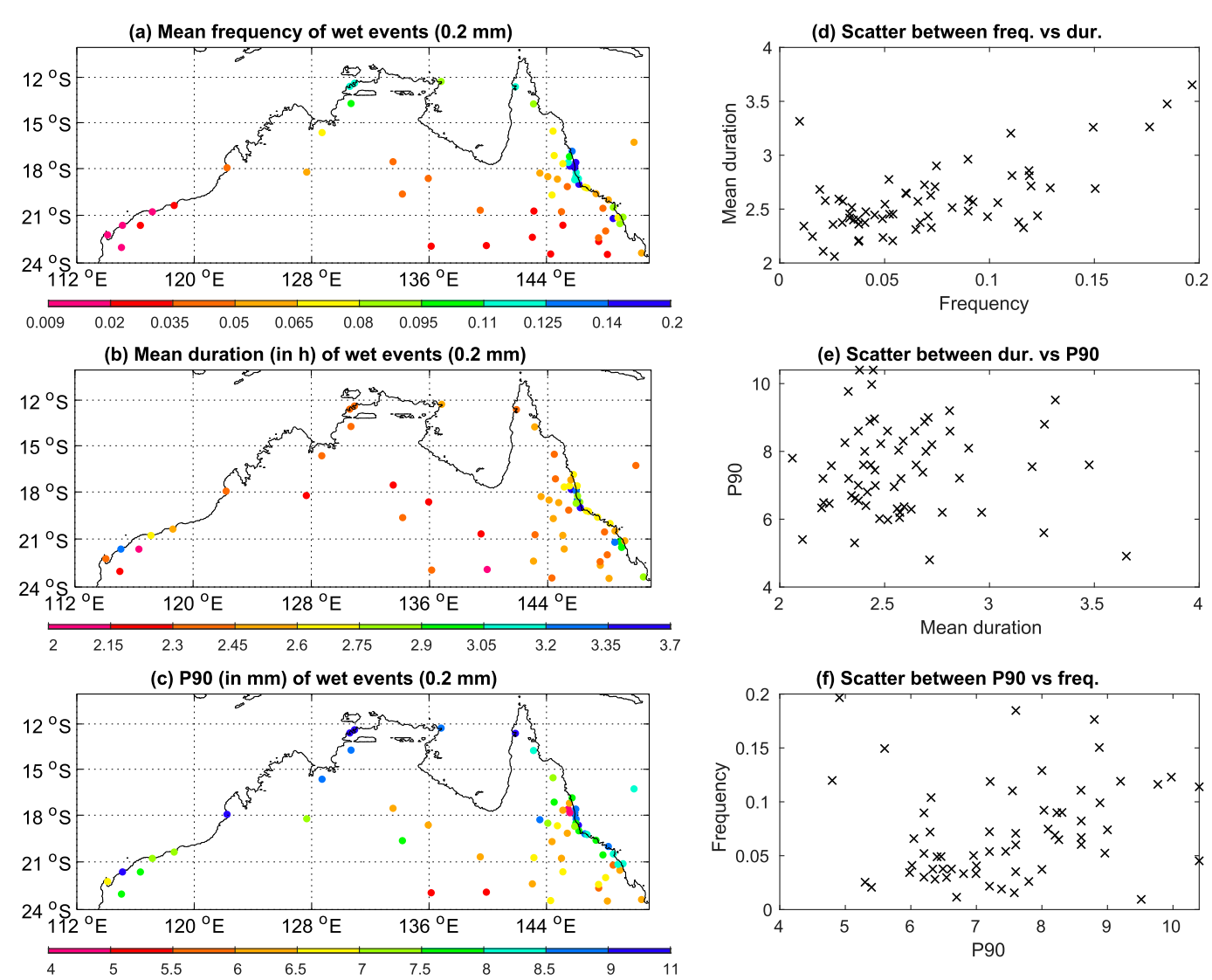

FIG. 2. (a) Relative frequency of hourly time steps receiving at least $0.2 \mathrm{~mm}$ of rainfall. (b) Mean duration in hours of wet spells receiving at least $0.2 \mathrm{~mm} \mathrm{~h}^{-1}$. (c) 90 th percentile (P90) of hourly wet hours receiving at least $0.2 \mathrm{~mm}$. (d) Scatterplot of relative frequency in abscissa vs mean duration in ordinate. (e) Scatterplot of mean duration in abscissa vs $\mathrm{P} 90$ in ordinate. (f) Scatterplot of P90 in abscissa vs relative frequency in ordinate.

increases the occurrence of wet hourly time steps, beyond the mean seasonal cycle. This approach acknowledges the fact that WTs and hourly rainfall are strongly locked onto the seasonal cycle due to the annual variation of the incoming solar radiation. The advantage is to partly retain (through the consideration of 3-day blocks) the temporal persistence and transitions of the WTs.

\section{Rainfall: Mean frequency, duration, and intensity}

Figure 1 shows the mean rainfall received in November-March alongside on the orography. The mean rainfall shows a southward gradient [from 1600 $1800 \mathrm{~mm}$ in the northern parts of Arnhem Land and the Cape York Peninsula (Darwin and Weipa) to 100 $200 \mathrm{~mm}$ in the southern margins (Exmouth and Longreach)] superimposed upon a strong coastalinterior contrast along the coast of Queensland. In the area between Mackay and Cairns, the rainfall clearly peaks along the coast, especially between Townsville and Cairns, where the coast becomes almost perpendicular to the moisture flux and is also located windward of the highest altitudes (at these latitudes) of the Great Dividing Range (Fig. 1). It is also striking that rainfall decreases rapidly moving inland from the coast, even for higher altitudes, and that the flat Willis Island receives far less rainfall than the coastal mainland. Such rainfall maxima at sea level or on the first windward slopes are due to the orographic lifting of warm and moist airstreams very close to its vapor saturation at sea level, leading to abundant precipitable water, while the rainfall decreases upward due to the decreasing amount of precipitable water in relation to rainfall depletion over the coast and the first windward slopes.

Figure 2 shows the mean climatology of the relative frequency of wet hours, the duration of wet events and the 90th percentile (P90) of the wet hours receiving $\geq 0.2 \mathrm{~mm}$ (these characteristics are also computed with a threshold of $1 \mathrm{~mm}$ to define wet hours, see Fig. A2), 
TABLE 3. Spatial average, standard deviation, and coefficient of variation (CV) of different characteristics of November-March rainfall including total amounts, frequency of wet hourly time steps $\geq 0.2 \mathrm{~mm}$ and $\geq 1 \mathrm{~mm}$, duration of wet spells (= consecutive wet hours receiving $\geq 0.2 \mathrm{~mm} \mathrm{~h}^{-1}$ and $\geq 1 \mathrm{~mm} \mathrm{~h}^{-1}$ ), and 90th percentile ( $\mathrm{p} 90$ ) of hourly wet time steps receiving $\geq 0.2 \mathrm{~mm}$ and $\geq 1 \mathrm{~mm}$. The last column gives the pattern correlation (among the 61 stations) with the total amount.

\begin{tabular}{|c|c|c|c|c|}
\hline & Spatial average & Spatial standard deviation & $\mathrm{CV}$ & Pattern correlation with total amount \\
\hline Total amount & $768 \mathrm{~mm}$ & $510 \mathrm{~mm}$ & 0.66 & 1 \\
\hline $\begin{array}{l}\text { Frequency of wet hourly time steps } \\
\quad \geq 0.2 \mathrm{~mm}\end{array}$ & 0.071 & 0.045 & 0.63 & 0.95 \\
\hline $\begin{array}{l}\text { Frequency of wet hourly time steps } \\
\quad \geq 1 \mathrm{~mm}\end{array}$ & 0.036 & 0.024 & 0.66 & 0.98 \\
\hline Duration of wet spells $\geq 0.2 \mathrm{~mm}$ & $2.58 \mathrm{~h}$ & $0.33 \mathrm{~h}$ & 0.13 & 0.53 \\
\hline Duration of wet spells $\geq 1 \mathrm{~mm}$ & $2.09 \mathrm{~h}$ & $0.19 \mathrm{~h}$ & 0.09 & 0.52 \\
\hline p90 of wet hourly time steps $\geq 0.2 \mathrm{~mm}$ & $7.46 \mathrm{~mm}$ & $1.32 \mathrm{~mm}$ & 0.18 & 0.45 \\
\hline p90 of wet hourly time steps $\geq 1 \mathrm{~mm}$ & $12 \mathrm{~mm}$ & $1.72 \mathrm{~mm}$ & 0.14 & 0.34 \\
\hline
\end{tabular}

while Table 3 summarizes the unweighted spatial average, standard deviation and coefficient of variation $(\mathrm{CV})$ of these variables with thresholds of both 0.2 and $1 \mathrm{~mm}$. The mean frequency mimics almost perfectly the seasonal amount of rainfall (Fig. 2), decreasing from the north to the south, except for along the eastern coast where a high maxima is observed between Cairns and Townsville (Fig. 2). Both the duration and the intensity revealed by the $\mathrm{p} 90$ show a homogeneous pattern (i.e., very low $\mathrm{CV}$ in space, see Table 3). Interestingly, the storms in Darwin and surrounding stations seem shorter (Fig. 2b) but more intense (Fig. 2c), reflecting the prevalence of short convective storms. We hypothesize that the low $\mathrm{CV}$ of duration is partly due to the hourly measurement resolution, which is not far from the average duration of a storm (Table 3). In consequence, the negative deviations are severely limited by the small difference between the mean and the lowest possible event duration of a single hour. But this effect does not hold for the intensity, since the spatial average is far above the detection threshold (i.e., $0.2 \mathrm{~mm}$ ). Moreover, there are physical reasons why the duration and intensity at the hourly time scale may be more homogeneous across space than the frequency. If the duration and intensity are mostly constrained by dominant atmospheric phenomena, such as deep moist convection in cumulonimbus, independently from the inclusion or not of this basic scale into larger phenomena, they should be nearconstant in space except for orographical forcing. This last mechanical forcing may be able to locally increase the intensity and duration of wet spells by adding a fixed lifting source for deep convection. We may then hypothesize that the spatial homogeneity may be even stronger for subhourly records while a daily (and longer) aggregation is expected to exacerbate the spatial contrasts, through the varying modulation of both the persistence and occurrence of wet events.

\section{Weather types}

\section{a. Mean atmospheric patterns and their seasonality}

This subsection analyzes the WTs in terms of their mean actual and anomalous low-level winds alongside their mean seasonal cycle and duration (Fig. 3). The WT occurrence is also compared with two independent surrogates of the regional-scale atmospheric circulation across tropical Australia. This includes the WRs (Table 1) estimated from the radio soundings at Darwin (Pope et al. 2009; Catto et al. 2012) and the times series of break, active and neutral phases of the regional-scale monsoon (Table 2). Additionally, the rainfall and wind indices as well as the WTs are shown in Fig. 4 for two contrasting seasons, that is, $1983 / 84$ and $1987 / 88$, previously analyzed in Wheeler and McBride (2005). The relationship between the onset and demise of the regional-scale monsoon on one hand and the WTs on the other hand is displayed in Fig. 5.

Figure $3 \mathrm{~g}$ suggests that WTs can be interpreted first of all as snapshots of the mean annual cycle with an alteration between east-southeast trade winds over most of the domain during the austral winter (WT1 and WT6, Figs. 3a and 3f, referred to as "trade wind" WTs) and westerlies, at least over the central part of Indonesia, during the austral summer monsoon from December to February (WTs 3-5, Figs. 3c-e, referred to as "monsoonal" WTs). The last WT (WT2, Fig. 3b) is mostly "transitional" between both families of contrasting WTs.

Figure 4 shows clearly that WTs may appear as transient short spells as well as longer sequences lasting more than 15 consecutive days (such as WT3 in February 1984). Their sequence is clearly more quasiperiodic in $1987 / 88$ than in 1983/84 in association with strong intraseasonal variability, probably related to the MJO; three active periods occur around late December, early February, and late March (usually associated with either WT4 or WT5). The main break periods are mostly 
(a) WT 1 [Trade 1]

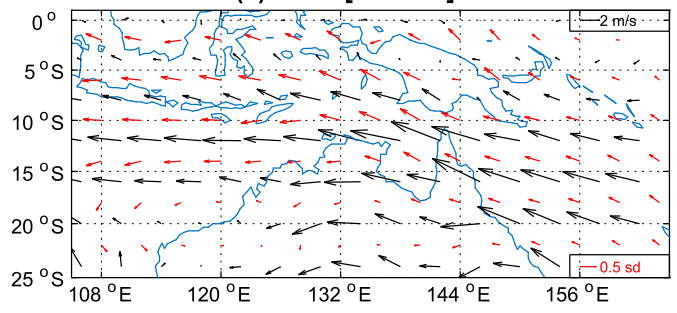

(c) WT 3 [Monsoonal East]

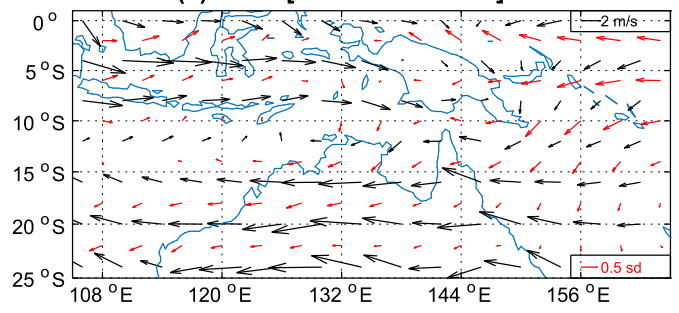

(e) WT 5 [Monsoonal West 2]

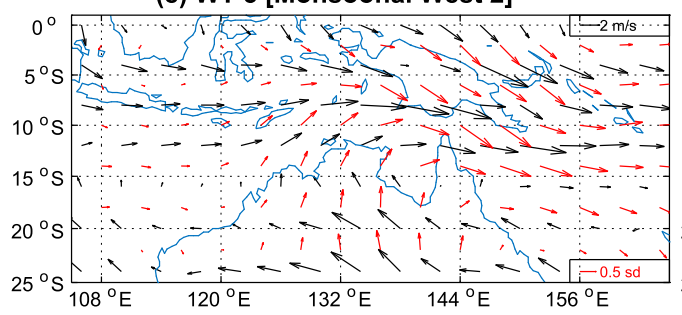

(g) Seasonal cycle of the occurrence of WTs

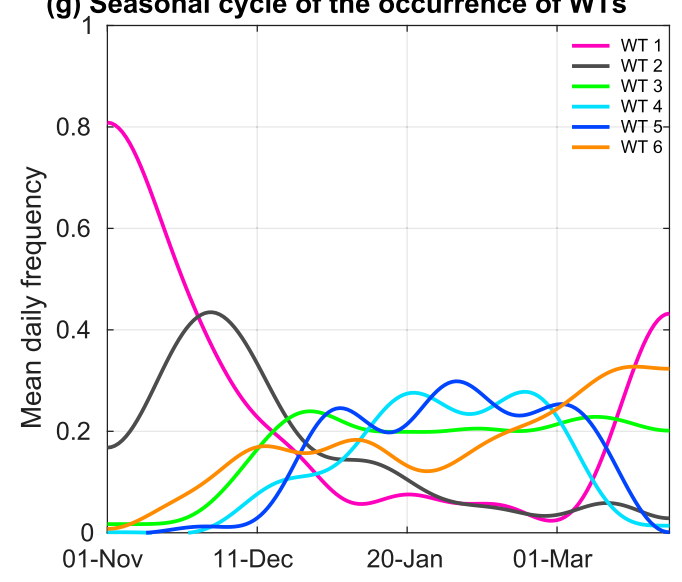

(b) WT 2 [Transitional]

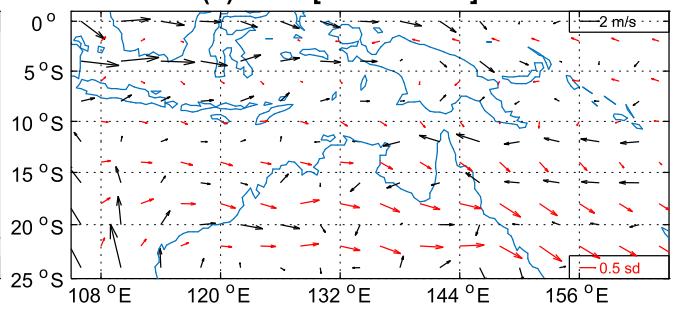

(d) WT 4 [Monsoonal West 1]

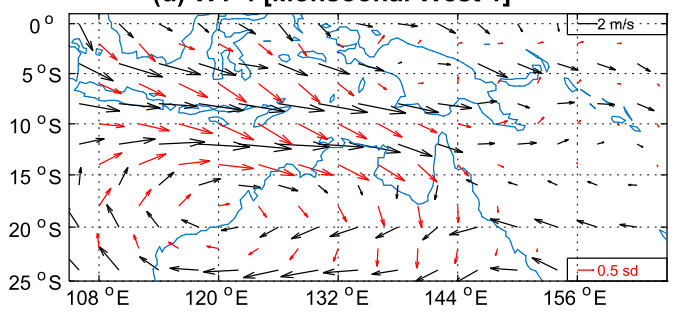

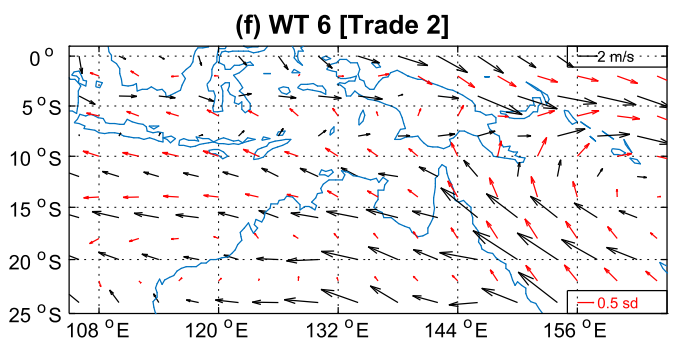

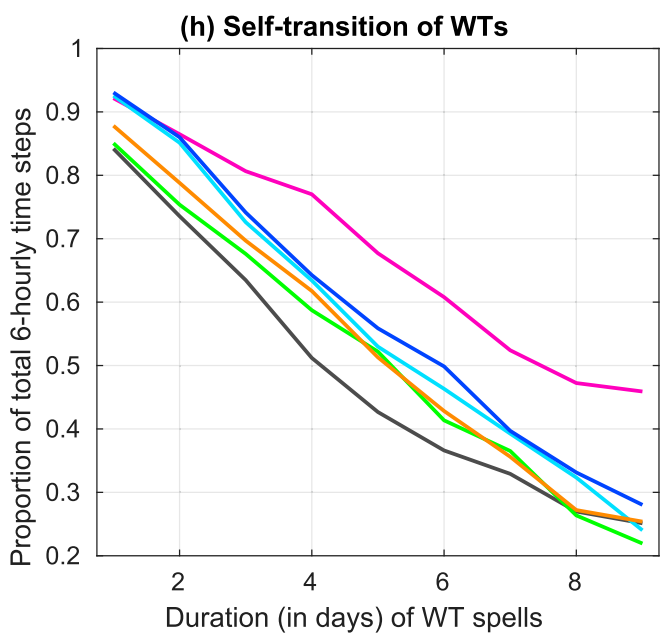

FIG. 3. (a)-(f) Mean raw winds (black vectors) and anomalies vs the climatological daily mean (red vectors) during each WT. Only the anomalies significant at the two-sided $95 \%$ level of either zonal or meridional component of the 850 -hPa winds are plotted. The significance is computed from 1000 random permutation of the seasonal sequences of WTs. For clarity, the winds are plotted every $4^{\circ}$ of longitude and latitude. (g) Mean relative frequency of occurrence of each WT. The raw mean is low-pass filtered with a recursive Butterworth filter with a cutoff at 1/30 cpd. (h) Proportion of 6-hourly WT belonging to a spell of consecutive WTs lasting at least 1-9 days (as indicated in abscissa). 
(a) $1983-84$

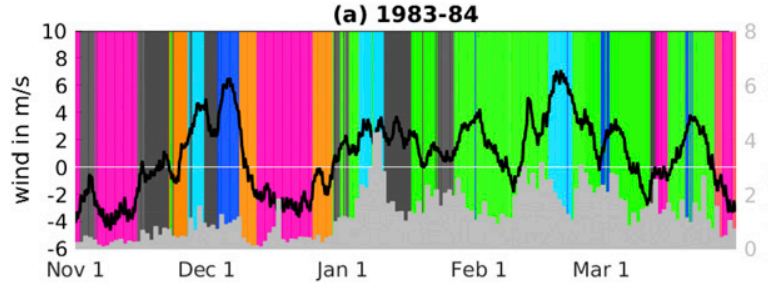

(b) $1987-88$

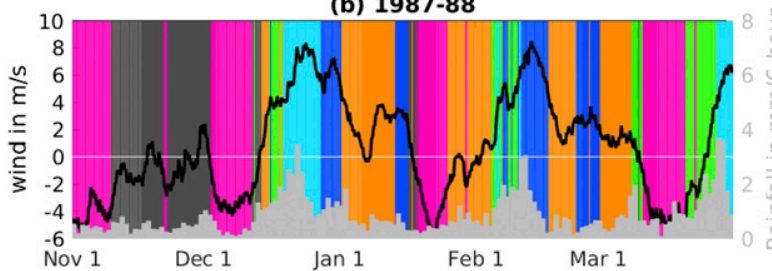

FIG. 4. Times series of the 6-hourly WTs (color bars; WT1 in magenta, WT2 in dark gray, WT 3 in green, WT4 in light blue, WT5 in dark blue, WT6 in orange), the monsoonal wind index (black line, left axis), and the monsoonal rainfall index (gray bars, right axis) for (a) 1983/84 and (b) 1987/88.

associated with either WT1 or WT6. The 1983/84 season shows a clearly different behavior with a high prevalence of WT3 from early January to mid-March while the start of the season from early November to late December 1983 fits better with the sequence observed in 1987/88, with two breaks (mostly WT1 and WT6) around mid-
November and mid- to late December around a short active period (mostly WT4 and WT5) around early December.

On average, WT1 is mostly prevalent in November and late March (Fig. 3g) and is characterized by generalized east-southeast trade winds, anomalously fast north of $12^{\circ} \mathrm{S}$ (Fig. 3a). WT1 is also the most persistent WT with more than $75 \%$ of time steps part of spells lasting at least 4 consecutive days (Fig. 3h). This WT matches mostly with the dry east or the east WR at Darwin (Pope et al. 2009) (Table 1) and with the MC WT1-2 and 6 (Moron et al. 2015a) (see Table 4). Trade winds are also anomalously strong in WT6 (Fig. 3f), which is less seasonal than WT1 (Fig. 3g), but a cyclonic curvature is visible toward the equatorial central Pacific, while the winds are weaker over central Indonesia (Fig. 3f). In fact, WT6 is strongly associated with the quiescent WT across the Maritime Continent (i.e., MC WT5) (Table 4), promoting regional-scale negative rainfall anomalies during the monsoonal season across the inner seas of the Maritime Continent. The dependency of WT6 with east WRs at Darwin (WR1, 3, and 5) is weaker than for WT1. As expected, WTs 1 and 6 are more (less) prevalent during break (active) periods (Table 2) and are not conducive to cyclonic activity across northern Australia (Fig. A4). In fact, $100 \%$ of the main break period during Tropical Warm Pool
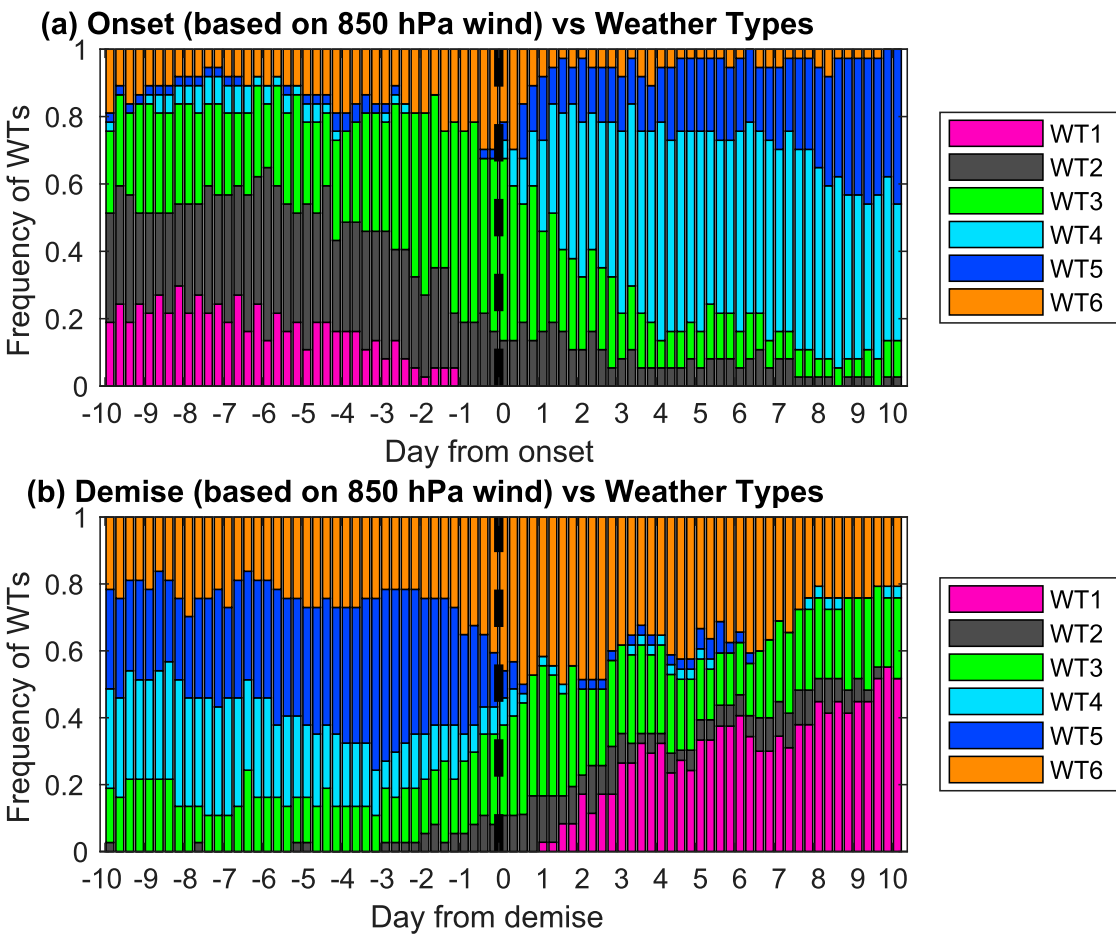

FIG. 5. Relative frequency of six WTs over a period spanning 10 days before to 10 days after (a) the onset and (b) the demise dates of the regional-scale monsoon defined from the monsoonal wind index. 
TABLE 4. Conditional frequencies between weather types (WT) and the WTs computed over the Maritime Continent (Moron et al. 2015a). The values are expressed as anomalous frequencies (vs expected frequencies in percentage) and the bold values are significant at the two-sided $95 \%$ level according to a random permutation (1000 times) of the Australian WT time series by season, such as the mean seasonal cycle is kept in the reshuffled sequences.

\begin{tabular}{lcccrrr}
\hline & WT 1 MC & WT 2 MC & WT 3 MC & WT 4 MC & WT 5 MC & WT 6 MC \\
\hline WT 1 AUS & +188 & $\mathbf{+ 1 2 4}$ & $\mathbf{- 8 1}$ & $\mathbf{- 1 0 0}$ & $\mathbf{+ 2 1}$ & $\mathbf{+ 2 7 6}$ \\
WT 2 AUS & $\mathbf{+ 7 9}$ & $\mathbf{+ 3 5}$ & $\mathbf{+ 7 6}$ & $\mathbf{- 6 6}$ & $\mathbf{- 5 2}$ \\
WT 3 AUS & $\mathbf{- 6 6}$ & $\mathbf{- 8 6}$ & $\mathbf{+ 1 6 7}$ & $\mathbf{- 4 8}$ & $\mathbf{- 2 8}$ & $\mathbf{- 7 9}$ \\
WT 4 AUS & $\mathbf{- 1 0 0}$ & $\mathbf{- 9 5}$ & -8 & $\mathbf{+ 1 7 9}$ & $\mathbf{- 9 4}$ & $\mathbf{- 1 0 0}$ \\
WT 5 AUS & $\mathbf{- 1 0 0}$ & $\mathbf{- 8 9}$ & $\mathbf{- 6 4}$ & $\mathbf{- 6 1}$ & $\mathbf{- 6 9}$ & $\mathbf{+ 1 3 2}$ \\
WT 6 AUS & $\mathbf{- 1 0 0}$ & $\mathbf{+ 3 3}$ & $\mathbf{- 6 6}$ & $\mathbf{- 8 4}$ \\
\hline
\end{tabular}

International Cloud Experiment (TWP-ICE) (May et al. 2008; Xie et al. 2010) (from 6 to 13 February 2006) belong indeed to WT6.

WTs 3-5 are typical of the Austral summer monsoon with a near constant frequency between mid-December and early March (Fig. 3g). WT3 shows a clear zonal monsoon shear line between $10^{\circ}$ and $14^{\circ} \mathrm{S}$ west of $130^{\circ} \mathrm{E}$, separating the near-equatorial westerlies from the subtropical trade winds (Fig. 3c). A regional-scale convergence is also visible around the Timor Sea (Fig. 3c), while the trade winds are faster than average east of $140^{\circ} \mathrm{E}$ (Fig. 3c). WT3 matches mostly with the moist east WR at Darwin (Table 1), while the cyclonic activity is anomalously strong over the Northwest quadrant of tropical Australia (Fig. A4). As expected, this WT strongly projects on the MC WT3 (Table 4) which is the wettest WT across the Maritime Continent (Moron et al. 2015a). WT4 shows a clear low pressure centered around $17^{\circ} \mathrm{S}, 120^{\circ} \mathrm{E}$ with a strengthened monsoon flow extending from the central part of Indonesia toward northern Australia (Fig. 3d). This WT projects strongly on the west deep WR at Darwin and prevails during active periods of the regional-scale monsoon (Tables 2 and 4). Seventy-five percent of the active period of TWP-ICE from 13 to 25 January 2006 (May et al. 2008; Xie et al. 2010) belongs to WT4. In contrast, break periods almost never occur during WT4 (Table 2). WT5 is slightly different with an eastward displacement of the cyclonic center relative to WT4, and projects mostly on the shallow west WR at Darwin (instead of the deep west WR for WT4). The highest cyclonic activity also shows a clear eastward shift between WT4 and WT5 (Fig. A4). As expected, WT4 and WT5 match strongly with the MC WT4 (Table 4), corresponding to the southernmost location of the ITCZ. Figure 5 shows that WT3 and WT4 occur mainly during the core of the regional-scale Australian monsoon. In particular, their frequency suddenly increases (decreases) right after the regional-scale onset (demise) of the monsoon.

Last, WT2 is most prevalent between WT1 and the monsoonal WTs (WTs 3-5), during the premonsoon season as defined by Drosdowsky (1996), but its climatological frequency hardly exceeds $\geq 10 \%$ after mid-January (Fig. 3g). This WT is characterized by very weak winds, especially across Northern Australia where the westerly anomaly almost cancels the usual trade winds, mostly south of $15^{\circ} \mathrm{S}$ (Fig. 3b). It is also the least persistent WT (Fig. 3h). The lack of any clear regional-scale pattern raises the issue of its physical nature. In fact, WT2 projects only moderately on the shallow west WR at Darwin (Table 1) and is related mostly to the neutral phase of the regional-scale monsoon (Table 2). Looking at a subsample of this WT2 during 1983/84 and 1987/88 seasons (not shown) shows different atmospheric patterns, far from the other well-characterized WTs and associated with small-scale features and usually weak winds. It is also interesting to note that the $900 \mathrm{hPa}$ wind composites of "light" and "moderate" rainfall regimes of Clark et al. (2018) characterized by isolated and small patches of rainfall across Northwestern Australia display also weak winds. The frequency of the light regime peaks also during the premonsoon period. WT2 may be related to the mixing of different atmospheric patterns sharing weak winds as well as small-scale atmospheric features. In fact, WT2 occurs mostly when the regional-scale wind index is close to zero in 1983/84 and 1987/88. In conclusion, WT2 is probably less "physical" than the other ones, but encapsulates situations sharing some common features, including weak winds and the absence of any regional-scale coherent atmospheric patterns revealed by the other WTs, thus emphasizing the role and impact of small-scale features.

\section{b. Impact of the diurnal cycle}

The impact of the diurnal cycle on wind anomalies and WTs is evaluated by considering wind anomalies between each 6-h slot and the daily mean, and then the frequency anomalies of each WT versus the 6-hourly time steps (Fig. 6). The 6-hourly wind anomalies versus the daily mean are computed independently on each month to explicitly consider the seasonal cycle, although they are in fact very similar across the season. Their amplitudes peak 

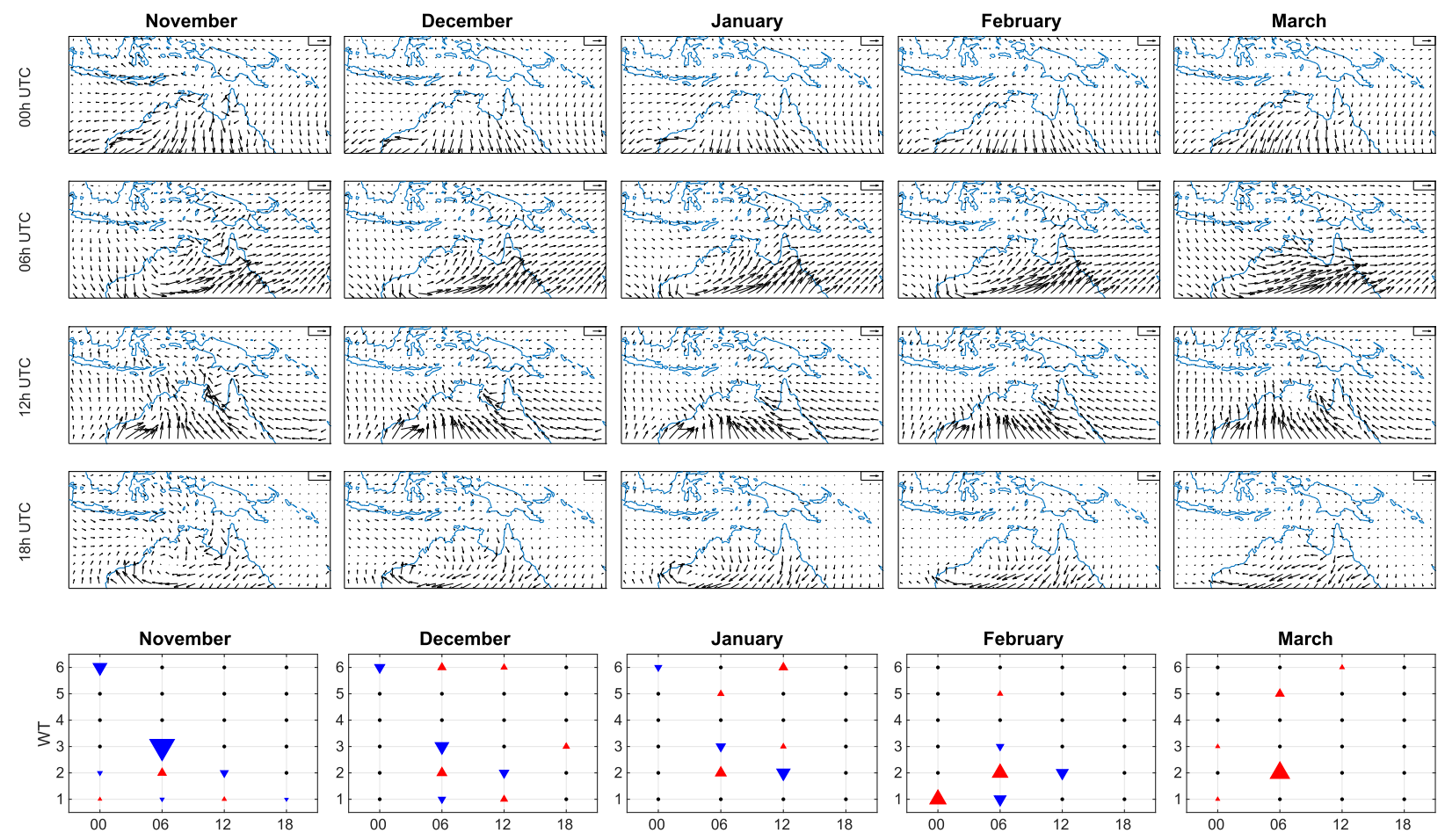

FIG. 6. (top four rows) Mean wind anomalies vs the daily mean by month and 6-h step. The middle hour of each 6-h time step is indicated on the left. (bottom row) Mean frequency of each WT expressed as anomalies vs the expected frequency. Blue lower (red upper) triangles indicate significant negative (positive) anomalies at the two-sided $95 \%$ level. A dot indicates that the anomaly is not significant at this level.

at around $1 \mathrm{~m} \mathrm{~s}^{-1}$ over Australia, in agreement with what is observed at the global scale (Dai and Slingo 1999). The amplitude of the diurnal cycle is also weak over the oceans due to negligible variation in the subdaily oceanic temperature. As expected, there is a rather symmetric variation between the 0000 UTC (corresponding roughly to the local morning) and the 1200 UTC (late afternoon and early night locally) time slots on the one hand, and between the 0600 UTC (afternoon locally) and the 1800 UTC (middle and late night locally) ones on the other hand (Fig. 6). The 0000 UTC (1200 UTC) time slot shows anomalous northerlies (southerlies) over continental Australia south of $18^{\circ}-20^{\circ} \mathrm{S}$, leading to anomalous divergence (convergence) over northern WA and the NT. The 1200 UTC (1800 UTC) time slot shows anomalous westerlies (easterlies) over continental Australia mostly south of $18^{\circ}-20^{\circ} \mathrm{S}$, thus weakening (strengthening) the usual trade winds.

The subdaily modulation of WT occurrence (Fig. 6) is the strongest for WT2, and second WT3. WT2 appears to occur more (less) frequently than expected during the 0600 (1200) UTC time slot, with increased anomalies from November to March for the former slot. This diurnal modulation is expected from Figs. 3 and 6 since the 0600 UTC anomalies (second row of Fig. 6) are rather similar to the wind anomalies associated with
WT2 (Fig. 3b). The diurnal modulation of WT3 is broadly reversed, with a weaker amplitude than for WT2 (Fig. 3g).

\section{c. Interannual and intraseasonal variability}

Interannual variations of the seasonal frequency of WTs (from 1 November to 31 March) is shown in Fig. 7a. None of the WT shows a significant trend over the 1979-2016 period. A major (and expected) control appears related to the ENSO phenomenon, with more (less) frequent WT1 and WT6 (WT3) during El Niño events and vice versa during La Niña events. In fact, the correlations between seasonal frequencies of WT1, WT3, and WT6 with Niño-3.4 averaged over November-March (NDJFM) equal 0.66, -0.75 , and 0.63 , respectively, while WT2, WT4, and WT5 are more independent to ENSO (absolute correlation of NDJFM frequency with Niño-3.4 $\leq 0.30$ ).

Figures $7 \mathrm{~b}-\mathrm{g}$ show the temporal evolution of each WT during the El Niño and La Niña events. This figure suggests that ENSO-related WT frequency is strongly modulated on subseasonal time scales. The positive (negative) anomaly of WT1 during warm (cold) ENSO events peaks around late November, while WT6 is more sensitive to ENSO around mid-December and early February. By contrast, the positive anomaly of WT3 is 
(a) Interannual variations of seasonal frequency of WT

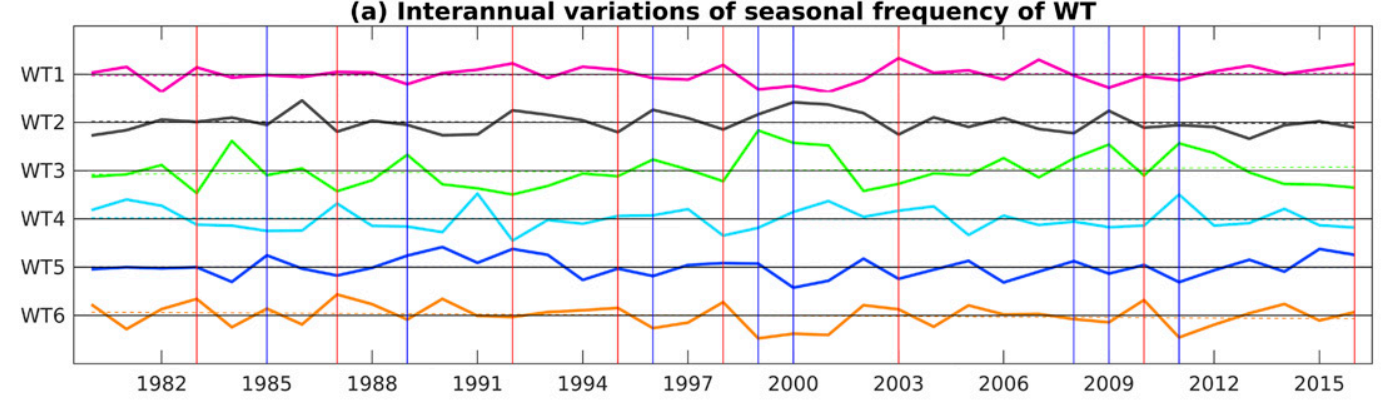

(b) WT 1

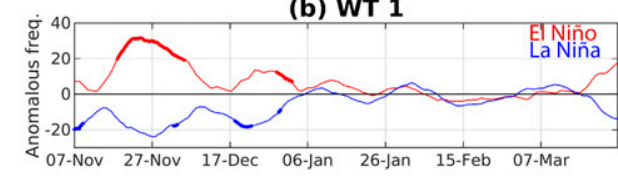

(d) WT 3

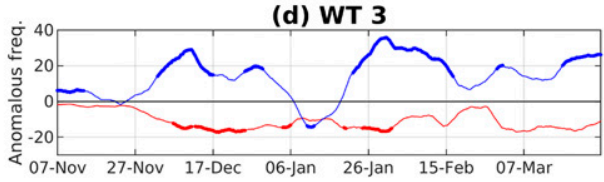

(f) WT 5

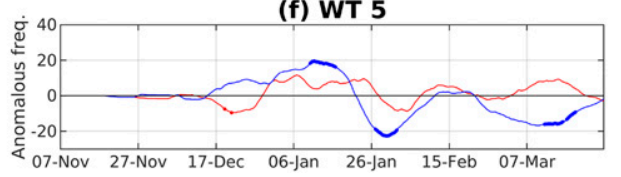

(c) WT 2

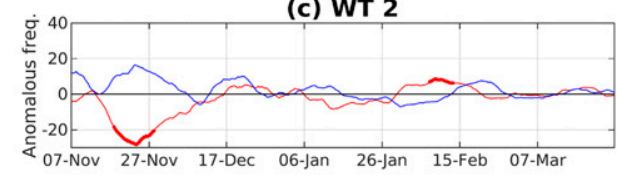

(e) WT 4

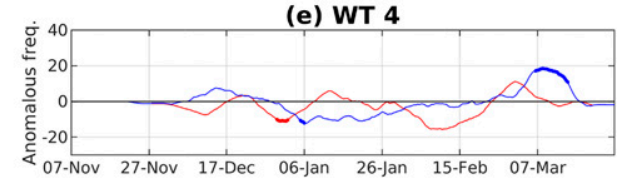

(g) WT 6

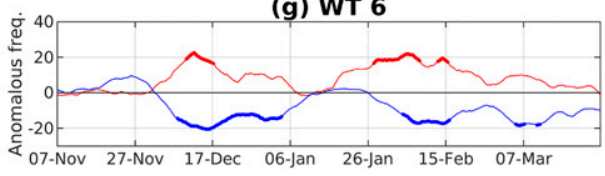

FIG. 7. (a) Interannual variations of the November-March (NDJFM) frequency of occurrence of each WT expressed as standardized anomalies vs the mean (in percentage), with each line separated by $100 \%$. The dashed line is the linear trend and the vertical red (blue) lines indicate El Niño (La Niña) events. (b)-(g) Anomalous frequency of each WT during El Niño (1982/83, 1986/87, 1991/92, 1994/95, 1997/98, 2002/03, 2009/10, 2015/16) and La Niña (1984/85, 1988/89, 1995/96, 1998/99, 1999/2000, 2007/08, 2008/09, 2010/11) events (expressed as percentage of the mean) defined in (a) in 11-day running windows centered on the date shown in abscissa. The dots represent significant anomalies according to 1000 random permutations of the seasonal sequences of WTs.

significant during long periods of La Niña in December, then from late January and February.

At the intraseasonal time scale, apart from WT2, all other WTs are significantly related to MJO phases, and it is striking that the modulation is very similar to the seasonality of WTs, that is, WT1 and WT6 are anomalously frequent in phases 1-3 and 8, when the intensified large-scale convection is located between the Caribbean basin and Africa (Fig. 8). The highest positive anomalies of WT3, WT4, and WT5 coincide with phases 4, 5-6, and 7 respectively, when the anomalous deep convection shifts from the Indian Ocean (WT3), toward the western Pacific (WT5). So, the WTs, beyond their trivial locking onto the annual cycle, can also be interpreted as snapshots of the MJO (with the exception of WT2). The intraseasonal modulation of WT occurrence by the MJO has also been evaluated independently on El Niño, La Niña, and neutral ENSO seasons (Figs. A5-A7). Despite some changes in the significance of anomalies, the MJO impact upon the WTs is robust across different ENSO states.

\section{d. Synthesis}

Table 5 provides a summary of the contributions of the four different time scales (i.e., diurnal cycle, MJO, annual cycle, and ENSO) onto the six WTs. Regarding the impact of diurnal and annual cycles, we simply compute the pattern correlation (pcorr hereafter) between the composite mean of raw $850 \mathrm{hPa}$ winds corresponding to each WT on the one hand and the 6-hourly and monthly means of the raw winds on the other hand. Regarding the impact of ENSO and the MJO, we compute pcorr between the composite mean of anomalous $850 \mathrm{hPa}$ winds (versus the climatological seasonal cycle) corresponding to each WT on the one hand, and the NDJFM mean of wind anomalies associated with the El Niño and La Niña events, and the wind anomalies associated with the eight MJO phases on the other hand.

The pcorr with the 6-h means (revealing the association with diurnal cycle) is the least stable (rows 2-3 of Table 5), that is, the highest pcorr observed with the zonal 
(a) WT 1

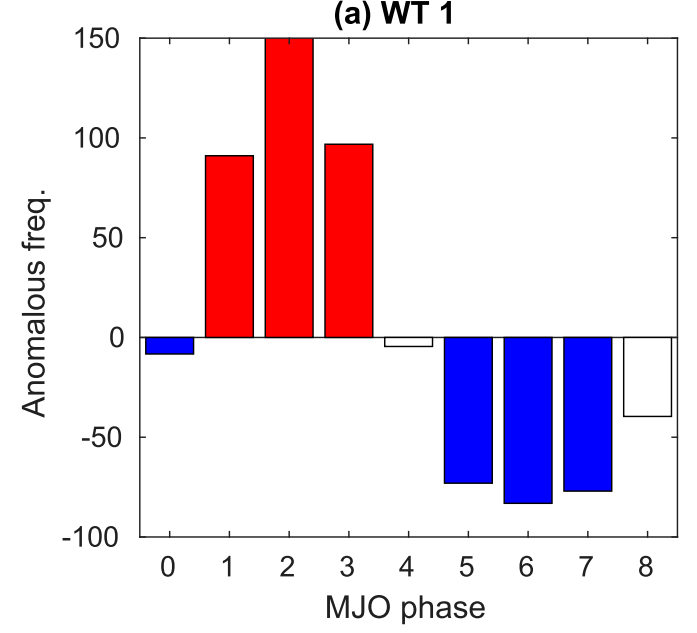

(c) WT 3

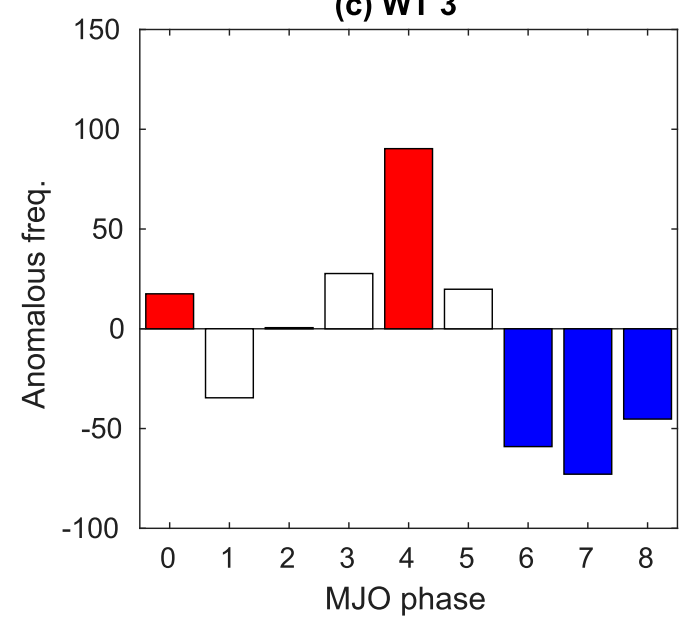

(e) WT 5

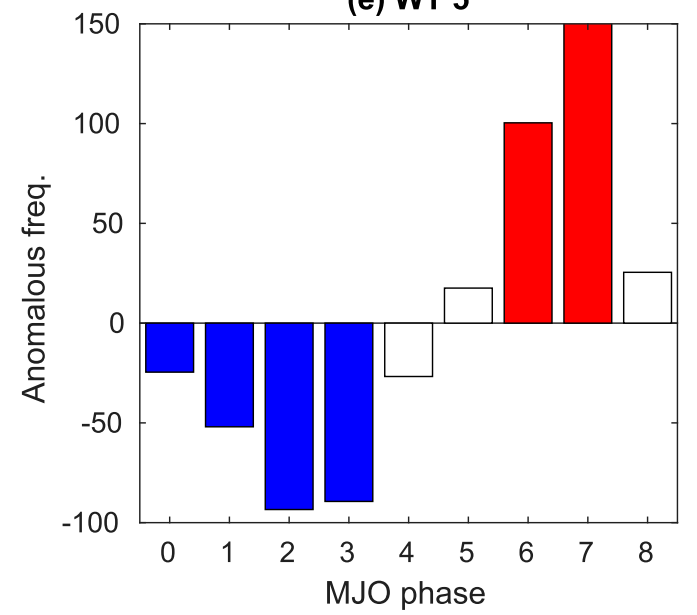

(b) WT 2

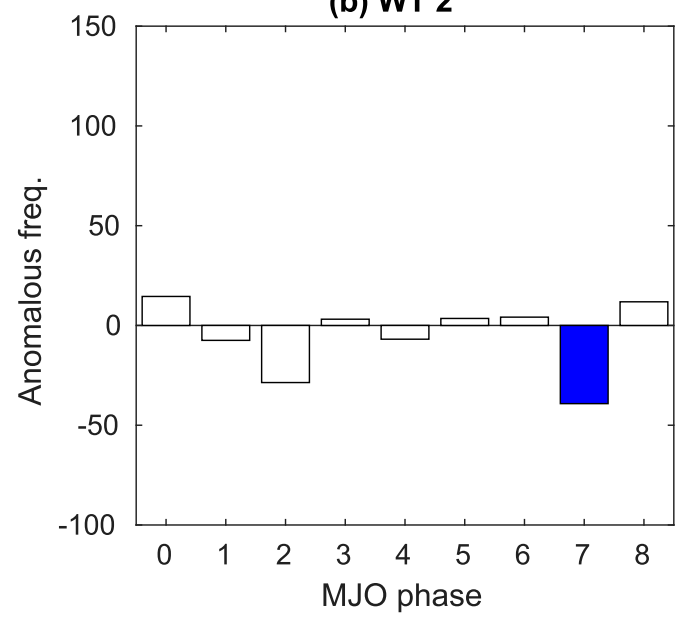

(d) WT 4

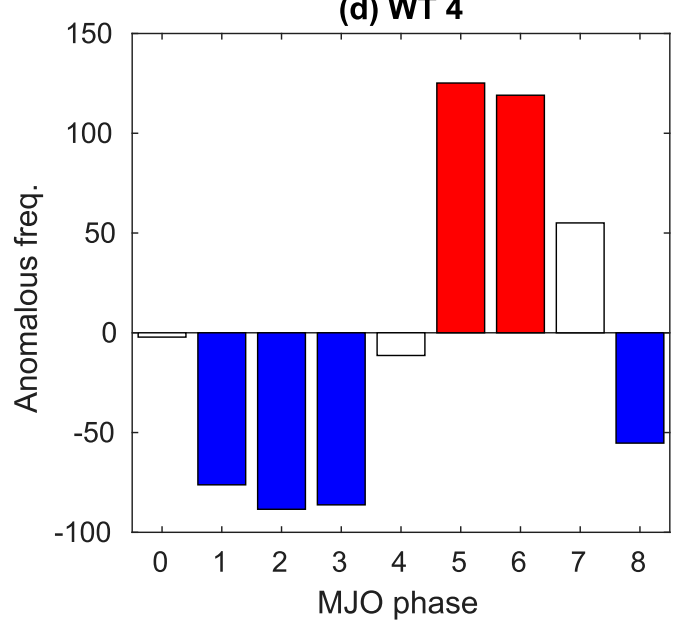

(f) WT 6

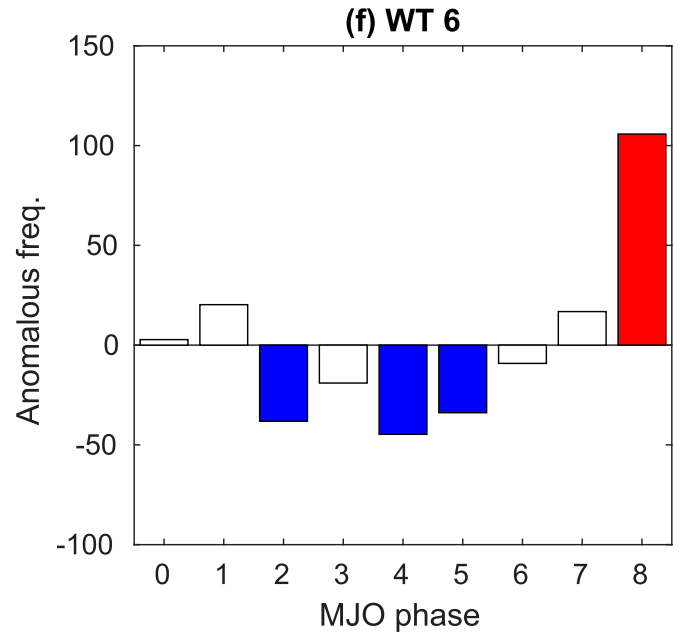

FIG. 8. Modulation of the occurrence of WT due to the MJO (expressed as the anomalies in percentage vs the expected frequency). The red (blue) bars show significant positive (negative) anomalies at the two-sided $95 \%$ level according to 1000 random permutation of the seasonal sequences of each WT. The 8 phases $(+$ phase 0 when the MJO is weak) of the MJO are defined from Wheeler and Hendon (2004). 
TABLE 5. Pattern correlations between (rows 2-3) composite of raw winds associated with each WT and the 6-hourly means of $U$ and $V$ at $850 \mathrm{hPa}$. The highest positive correlation (among the four 6-h slots) for each WT is indicated with the corresponding central hour of a 6-h time window in parentheses; (rows 4-5) composite of raw winds associated with each WT and the monthly means of $U$ and $V$ at $850 \mathrm{hPa}$ between November and March. The highest positive correlation (among the 5 monthly means) for each WT is indicated with the corresponding month in parentheses; (rows 6-7) composite of anomalous wind (vs the mean seasonal cycle) associated with each WT and the seasonal anomalies of $U$ and $V$ at $850 \mathrm{hPa}$ associated with either El Niño (EN) or La Niña (LN) events used in Fig. 7. The highest positive correlations (among either EN or LN composite) for each WT is indicated with the corresponding event in parentheses; (rows 8-9) composite of anomalous wind (vs the mean seasonal cycle) associated with each WT and the composite anomalies of $U$ and $V$ at $850 \mathrm{hPa}$ associated with the eight MJO active phases. The highest positive correlation (among the eight MJO phases) for each WT is indicated with the corresponding phase in parentheses.

\begin{tabular}{|c|c|c|c|c|c|c|}
\hline & WT1 & WT2 & WT3 & WT4 & WT5 & WT6 \\
\hline$U 6 \mathrm{~h}$ & 0.54 (1200 UTC) & 0.58 (0600 UTC) & 0.90 (0000 UTC) & 0.83 (1800 UTC) & 0.84 (1800 UTC) & 0.90 (0600 UTC) \\
\hline$V 6 \mathrm{~h}$ & 0.70 (0000 UTC) & 0.78 (1800 UTC) & 0.84 (1200 UTC) & 0.81 (1800 UTC) & 0.81 (1200 UTC) & 0.90 (0600 UTC) \\
\hline$U$ seasonal & 0.96 (Nov) & $0.76(\mathrm{Dec})$ & 0.89 (Jan) & $0.94(\mathrm{Feb})$ & 0.94 (Feb) & 0.93 (Mar) \\
\hline$V$ seasonal & 0.80 (Nov) & $0.86(\mathrm{Dec})$ & 0.87 (Jan) & 0.84 (Jan) & $0.86(\mathrm{Feb})$ & 0.95 (Mar) \\
\hline$U$ ENSO & $0.66(\mathrm{EN})$ & $0.45(\mathrm{LN})$ & $0.80(\mathrm{LN})$ & $0.46(\mathrm{LN})$ & $0.23(\mathrm{EN})$ & $0.64(\mathrm{EN})$ \\
\hline$V$ ENSO & $0.27(\mathrm{EN})$ & $0.42(\mathrm{LN})$ & $0.80(\mathrm{LN})$ & $-0.0(\mathrm{EN})$ & $0.10(\mathrm{LN})$ & $0.50(\mathrm{EN})$ \\
\hline$U \mathrm{MJO}$ & $0.88(2)$ & $0.89(3)$ & $0.85(4)$ & $0.76(5)$ & $0.85(7)$ & $0.66(8)$ \\
\hline$V \mathrm{MJO}$ & $0.85(2)$ & $0.33(5)$ & $0.60(4)$ & $0.40(5)$ & $0.73(7)$ & $0.58(8)$ \\
\hline
\end{tabular}

and meridional components is not systematically associated with the same time of the day for a given WT. It suggests that even if the diurnal cycle influences the occurrence of the WTs (Fig. 6), it does not provide the strongest forcing. By contrast, WTs strongly project onto the mean annual cycle with pcorr always exceeding 0.84 . Regarding ENSO, the wind anomalies of WT3 project very strongly onto the seasonal mean of La Niña events, while WT1 and WT6 (and especially their zonal components) project moderately onto the seasonal mean of El Niño events. As shown in Fig. 8, the WTs (especially WT1 and WTs 4-6) project strongly onto MJO phases. Last, it is interesting to note that the minimum averaged pcorr (using the impact of the seasonal cycle, ENSO, and the MJO) are observed for WTs 4-5 and WT2 ( $\leq 0.62$ versus pcorr $\geq 0.71$ for the remaining $3 \mathrm{WTs}$ ), reinforcing the hypothesis that these WTs must be strongly impacted by other processes not considered in this analysis, such as transient and relatively smaller-scale phenomena.

\section{Links between weather types and subdaily to multiday rainfall characteristics}

\section{a. WTs versus regional-scale daily rainfall}

Figure 9 shows actual GPCP rainfall contingent on WT but also significant anomalies where the effect of the seasonal cycle is removed. As expected from the mean seasonality of the WTs (Fig. 3f), WT1, WT2, and WT6 are drier than WTs $3-5$, especially across northern Australia for WT4 (Fig. 9d). It is interesting to note that for WT2, rainfall anomalies are significantly positive for most of the Australian landmass, consistent with the light and moderate regimes of Clark et al. (2018), while they are significantly negative over the subequatorial seas east of $130^{\circ} \mathrm{E}$ (Fig. 9b). The positive rainfall anomalies shift eastward from WT3 (Fig. 9c) to WT5 (Fig. 9e), reflecting the eastward propagation of the MJO. Figure A3 shows the contribution of each WT to the total rainfall received in all available time steps for each station. As expected, the "monsoonal" WTs 3-5 contribute the most to the total rainfall.

\section{b. WTs versus diurnal cycle of rainfall}

The mean diurnal cycle of rainfall is first computed at each rain gauge as the mean hourly rainfall and then smoothed with a low-pass filter (cutoff at $1 / 6 \mathrm{cph}$ ) and standardized versus the overall mean of hourly rainfall across all stations. This step enables the differentiation of both wettest versus driest stations and wettest versus dry hours. The corresponding matrix of $24 \mathrm{~h}$ by 61 stations is clustered using the $k$-means procedure. A solution with $k=3$ [significant at the one-sided $95 \%$ level of significance (not shown)] leads to the following clustering (Fig. 10): the first group includes most of the interior stations plus the driest ones of the Western Australia around Exmouth; the second group includes the wettest stations over the east coast of Queensland plus Weipa and both stations in Darwin; the third group includes mostly the coastal stations. Figure 10 also shows the mean hourly rainfall (in LST) averaged for a set of days, receiving at least $1 \mathrm{~mm}$ and during which the four 6-h time slots belong to the same WT. The phase of the diurnal cycle during wet days is only weakly impacted by the WTs. WT2 is related to a peak in late afternoon for the three groups of stations, consistent with local scattered thunderstorms mostly driven by the diurnal cycle. Stations belonging to group 2 are weakly (strongly) 

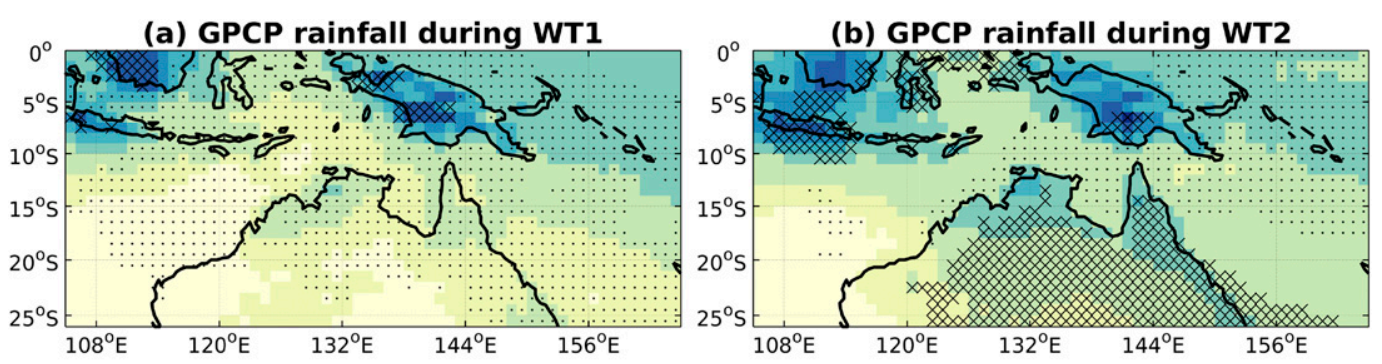

(c) GPCP rainfall during WT3
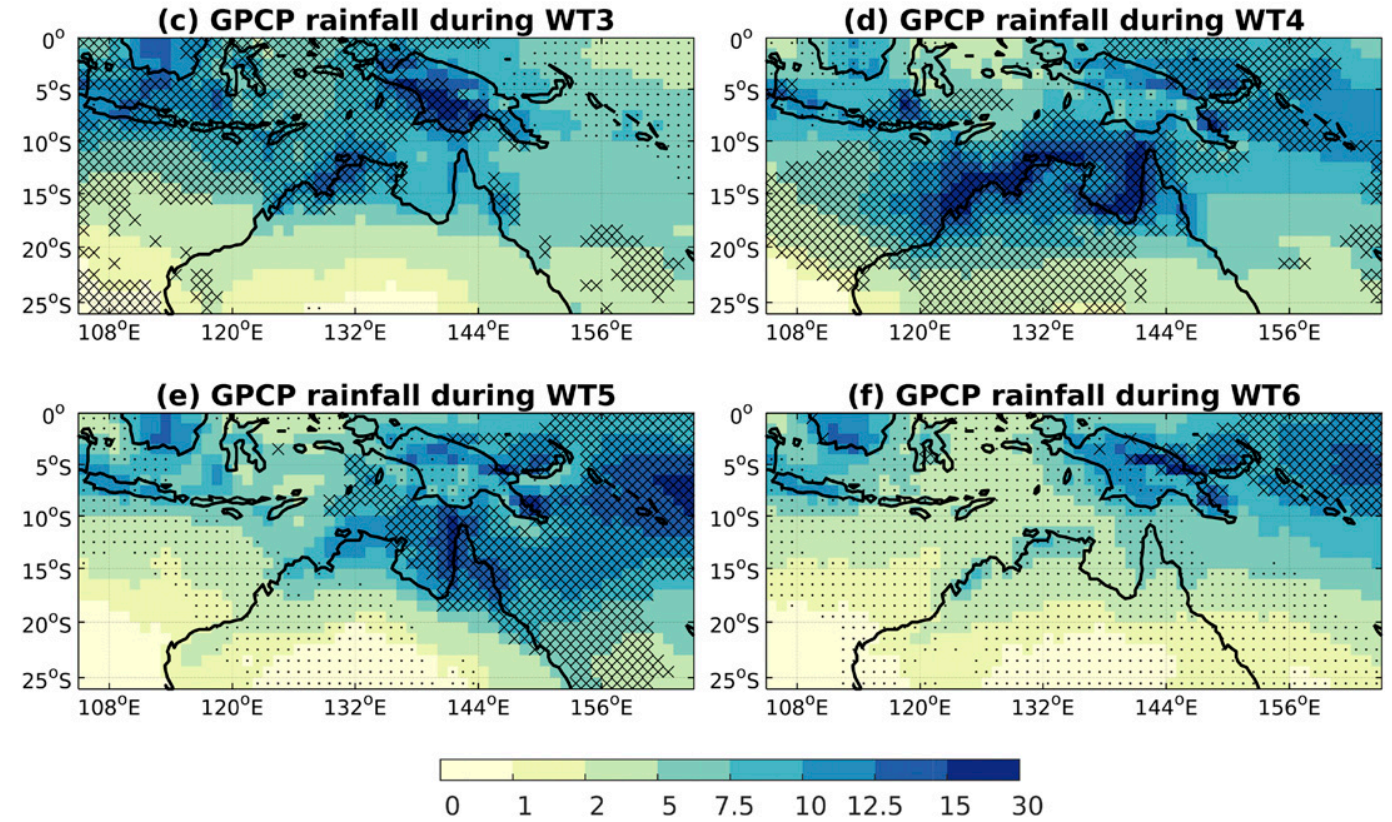

FIG. 9. Actual (shadings) and anomalous (black dots, significant negative anomalies; crosses, significant positive anomalies at the two-sided 95\% level vs the climatological daily mean) GPCP daily rainfall (in millimeters) during the WTs. Note the nonlinear color scale.

influenced by the diurnal cycle (WTs). Rainfall is now clearly higher for WTs 4-5 than for WT 1 and 6 . The impact of the WT on the diurnal cycle of rainfall is intermediate for group 3.

In summary, the phase of the diurnal cycle during wet days is almost never modified (except for WT2 in group 2 and 3 with a similar peak in late afternoon) while the hourly mean rainfall during wet days is weakly (for group 1) to strongly (for group 2, mostly on eastern and northern coasts) impacted by the occurrence of the WTs (i.e., WT1 and WT6 are anomalously dry while WTs 4 and 5 are anomalously wet throughout the day).

\section{c. WTs versus subdaily to multiday rainfall characteristics}

Figure 11 shows the anomalous frequency and duration of the weighted spatial averages across the 61 stations. WTs 3,4 , and 5 increase the frequency of wet hours beyond what is expected by the seasonal cycle, while WT1 and WT6 decrease it (Fig. 11a). For the duration (Fig. 11b), WT1, WT2, and WT6 (WTs 4-5) are associated with shorter (longer) wet events than what we would expect from their seasonality.

Regarding the intensity (Fig. 12), it is striking that the behavior is rather different for short time scales $(1 \mathrm{~h}$ and secondary, 3 and $6 \mathrm{~h}$ ) and daily and longer time scales. In this latter case, the monsoonal WTs, especially WT4 and WT5, contribute to the wettest deciles, while the dry WTs, especially WT1 and WT6, contribute mostly to the driest deciles. In other words, it rains frequently and strongly in WT4 and WT5 while it rains rarely and weakly in WT1 and WT6, in agreement with results based on daily rainfall from GPCP (Fig. 9). Interestingly, at the hourly time scale, WT2 (featuring weak synoptic forcing) shows the same positive anomaly as WT5 for the last decile while anomalies are clearly negative across daily and longer time scales. In other words, WT2 is associated with short but intense rainfall. 
(a) Clustering of mean diurnal cycle

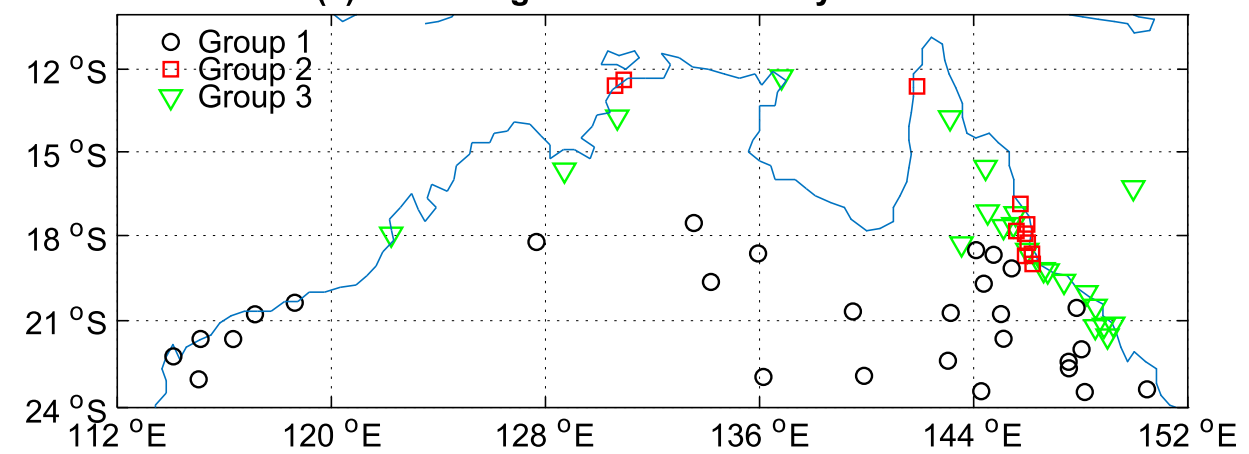

(b) Group 1

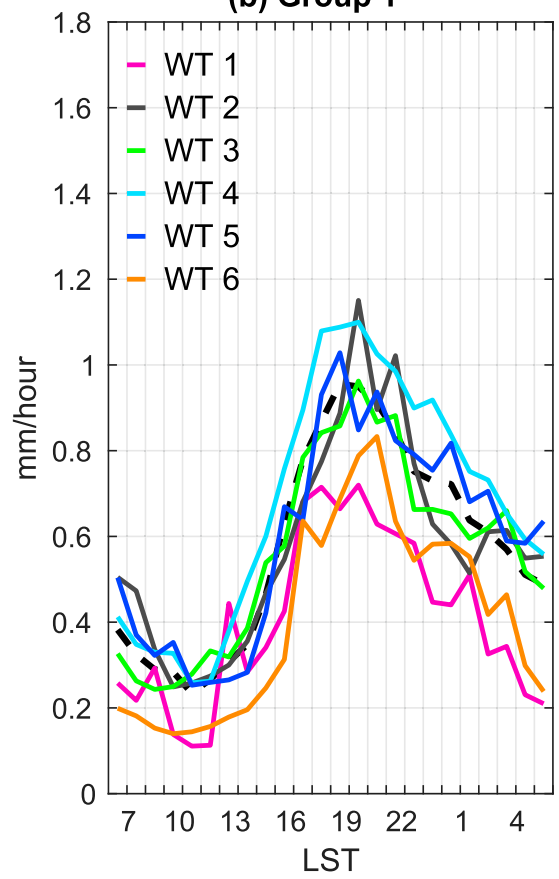

(c) Group 2

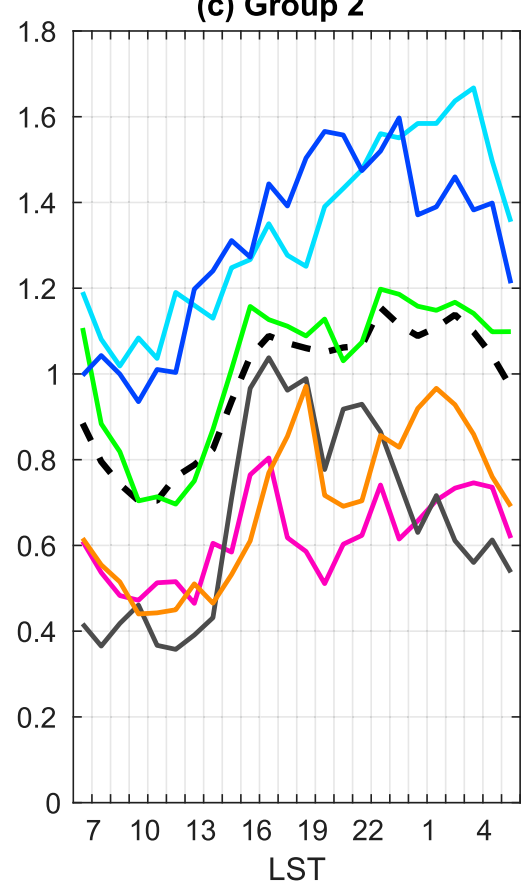

(d) Group 3

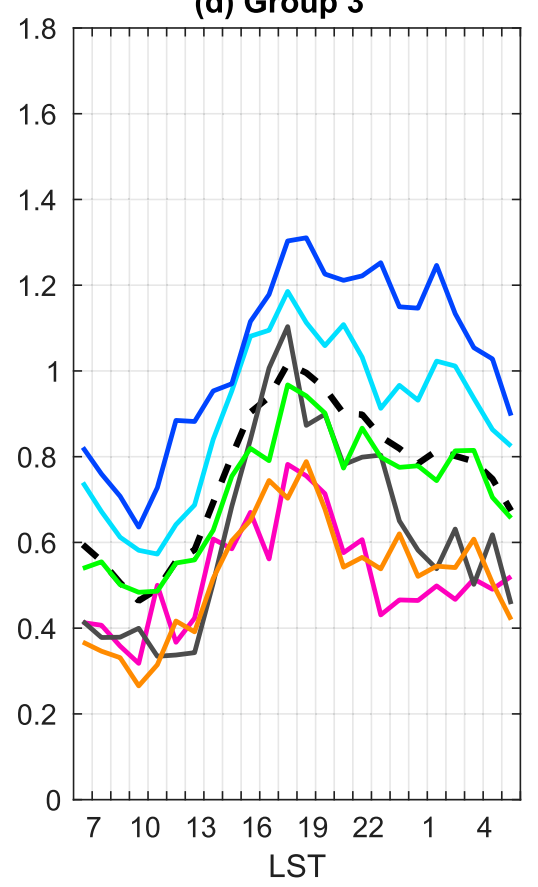

FIG. 10. (a) Clustering of the mean diurnal cycle into 3 groups using $k$ means. The mean diurnal cycle is computed from all available days without any missing entries and the hourly means are low-pass filtered with a cutoff at $1 / 6 \mathrm{cpd}$. The overall mean across all hours and stations is removed before the clustering. (b)-(d) Mean hourly rainfall (mean in dashed black and WT in color) for each cluster (only days receiving $\geq 1 \mathrm{~mm}$ and during which the four 6-hourly WT are identical are averaged for each station and then averaged by cluster).

Figure 13 details the spatial pattern of rainfall anomalies for both frequency and duration. Negative anomalies of wet hours frequency are evident for WT1 and WT6, with significant anomalies for most of the stations. By contrast, WT4 leads to a significantly increased frequency for most of the stations while WT2 leads to an increased frequency of wet hours for the interior of eastern Australia and decreased frequency along the coast. Last, WT5 is associated with more frequent wet hours over most of Queensland, while the frequency is lower than expected over the interior of the Northern Territory. The local-scale anomalies for event duration are usually weaker; WT1, WT2, and
WT6 lead to shorter wet spells while WT4 leads to longer ones. As for frequency, WT5 is associated with a contrasting pattern, with longer wet sequences especially along the eastern coast of Queensland, and shorter wet spells over the interior of the Northern Territory.

Figure 14 details the spatial pattern of the anomalous frequency of the last decile (i.e., local-scale rainfall above the 90th percentile) for five time steps $(1,12,24$, 72 , and $120 \mathrm{~h}$ ). It is clear that WT2 (characterized by weak winds) is related to more extreme rainfall than expected with significant positive anomalies across the York Peninsula at the hourly time scale only. Extremes 
(a) Frequency of wet 1-h slots

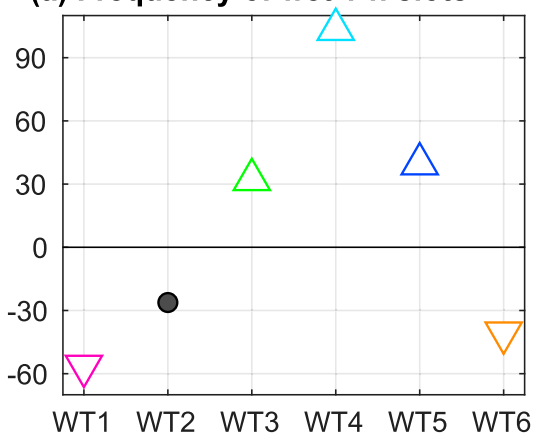

(b) Duration of wet events

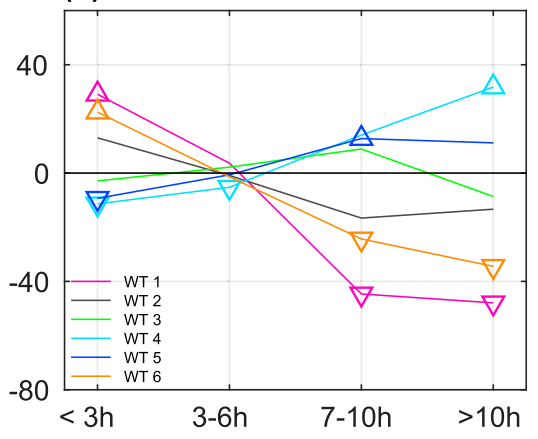

FIG. 11. Weighted spatial average of the local-scale anomaly (expressed as a percentage vs the expected value; see text) during the WTs. (a) The anomalous frequency of wet hourly time steps defined using a threshold of $0.2 \mathrm{~mm} \mathrm{~h}^{-1}$. Dot indicates that the spatial anomaly is not significant, while the upper (lower) triangles show positive (negative) anomaly significant at the two-sided $95 \%$ level. (b) The anomalous duration of wet events (from hourly data) defined using a threshold of $0.2 \mathrm{~mm} \mathrm{~h}^{-1}$ for four classes of duration shown in abscissa.

across longer time scales are less frequent than expected in WT2, highlighting the contrasting responses of rainfall extremes across different time scales and the importance of small-scale convective processes under weak synoptic forcing in initiating hourly rainfall extremes across at least the York Peninsula. Note also that WT5 leads to significant positive anomalies, mostly over Queensland, but that a few stations in the interior record negative anomalies, especially over $24 \mathrm{~h}$. WT6 appears to be drier than usual, especially for time scales longer than a day. Overall, it is readily apparent that the modulation of rainfall extremes by WTs is best manifested at daily or multiday time scales, while the distribution of subdaily rainfall extremes is more uniform across WTs.

As a synthesis, Fig. 15 shows the outputs of a simple analytical decomposition of the total amount of rainfall in $N$ consecutive hours into different terms (Moron et al. $2015 b)$. The total amount of rainfall $(R)$ for $N$ consecutive hours equals the product of the mean intensity of rainfall during wet hours $(\bar{I})$ and the number of wet hours $\left(F_{w}\right)$, which can be further decomposed into the number of wet spells $\left(F_{\mathrm{ws}}\right)$ and the mean length of wet spells $\left(\bar{L}_{\mathrm{ws}}\right)$. So, $R=\bar{I} \times F_{\mathrm{ws}} \times \bar{L}_{\mathrm{ws}}$. At the hourly time scale, this decomposition is obviously not possible but $R$ may be still expressed as the product of $\bar{I}$ by $F_{w}$. The decomposition is made for each station for running 24,72 , and 120 consecutive hours belonging to the same WT. Running temporal windows are used here to increase sample sizes. The five terms (i. e., $R, \bar{I}, F_{w}, F_{\mathrm{ws}}, \bar{L}_{\mathrm{ws}}$ ) are averaged for each WT and then standardized by the "climatological" averages (i.e., independent of the occurrence of the WTs). This is slightly different from a "real" climatological average since we averaged only those time sequences when WT persists during $N$ consecutive hours. Figure 15 shows the 25th, 50th, and 75th quantiles across the 61 stations. We must remind the reader here that the availability of gauges over-represents the east coast of Queensland. Once again, WTs modulate mostly the frequency of wet hours first (Fig. 15b), matching approximately what is observed for the total rainfall (Fig. 15a), while anomalies of the mean length of wet spells (Fig. 15e) are almost constant across the stations and the WTs and are independent on the temporal aggregation. The WT modulation on $\bar{I}$ is subtle and differs among the WTs (Fig. 15c). At the hourly time scale, as already suggested by Figs. 12 and 14, the spatial variations of anomalies are weak and the largest positive anomalies are observed during WT2 (and secondary WT5). When the temporal aggregation is $\geq 24 \mathrm{~h}$, the positive anomalies tend to peak during WT4 and WT5, then during WT2. The intensity is anomalously negative, as expected, for both trade-wind WTs, that is, WT1 and WT6 (Fig. 15c).

\section{Discussion and conclusions}

As elsewhere in the tropical zone (Moron et al. 2015a, 2016), WTs extracted from actual low-level winds may be first interpreted as a combination between the fingerprints of the seasonal cycle (and to some extent the diurnal cycle), and the main forcings at interannual (ENSO) and intraseasonal (MJO) time scales (Table 5). In other words, the occurrence of a specific 6-hourly pattern reflects the superimposition of periodic and quasiperiodic, as well as intermittent but recurrent, forcings; the intermittent nonrecurrent or too small features being 
Intensity of wet events (threshold $=0.2 \mathrm{~mm} \times \mathrm{L}$ )
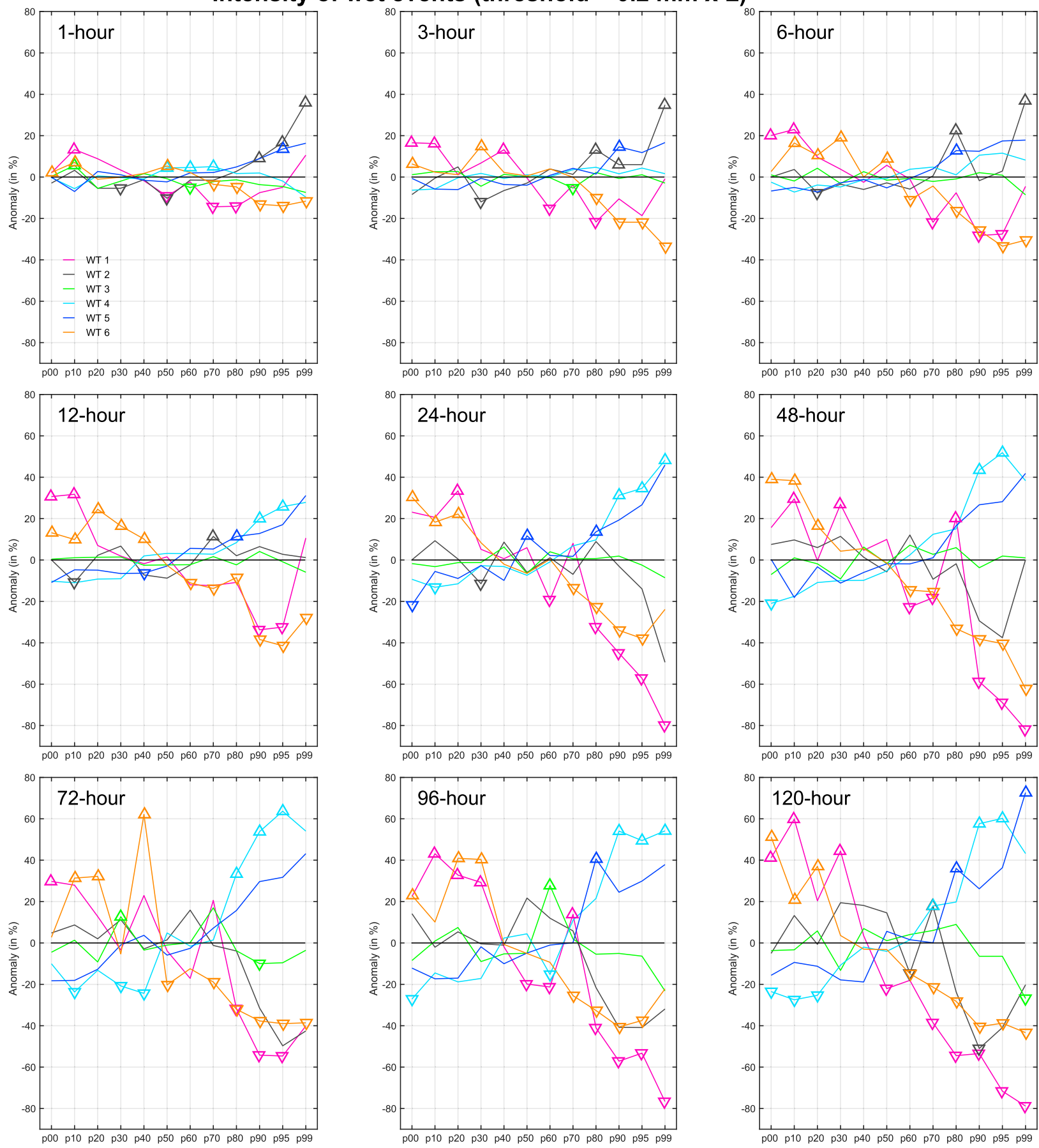

FIG. 12. Weighted spatial average of the local-scale anomaly (expressed as a percentage vs the expected value) during the WTs. The local-scale frequency of deciles (p00 is for the first decile, p10 is for the second decile, ..,p90 is for the 10th decile) as well as the 95th (p95) and 99th (p99) percentiles of wet time steps estimated from 1, 3, 6, 12, 24, 48, 72, 96, 120 consecutive hours are spatially averaged. The time steps are considered as wet as soon as they receive at least $0.2 \mathrm{~mm} \times L$, where $L$ is the length (in hours) of the time step (i.e., a 1-h time step is wet when it receives $\geq 0.2 \mathrm{~mm}$ and a 5-day time step is wet when it receives $\geq 24 \mathrm{~mm}$ ). The significance is computed as the difference between observed anomaly and the expected one estimated by 1000 random permutation of the WT sequences by blocks of 3 consecutive days in nonoverlapping 15 days. Lower and upper triangles show significant negative and positive anomalies respectively at the two-sided $95 \%$ level. 

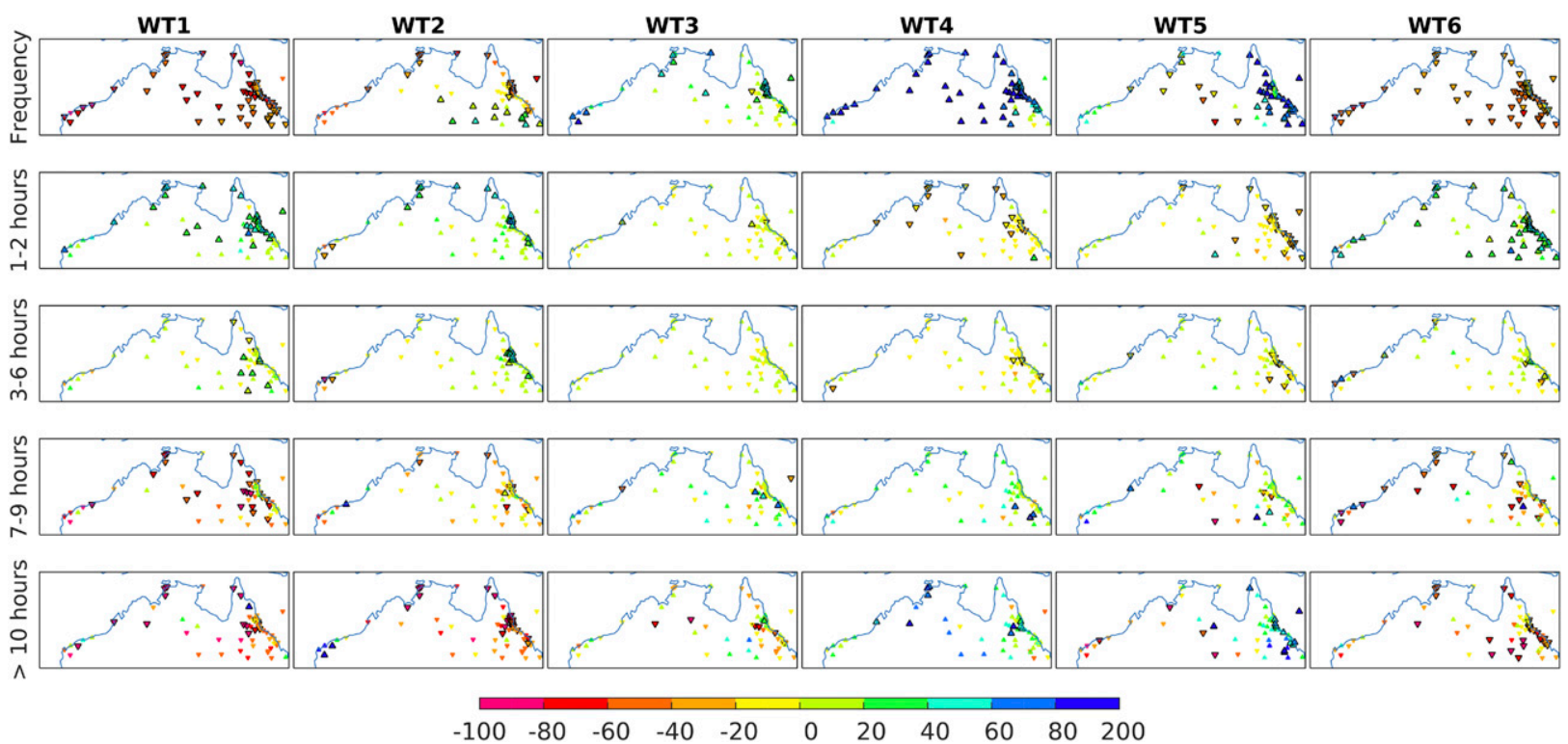

FIG. 13. Anomalous (lower triangle $=$ negative anomaly, upper triangle $=$ positive anomaly) frequency (expressed as a percentage vs the expected value) of (top row) wet hourly time steps and (rows 2-5) very short (1-2 h), short (3-6 h), medium (7-10 h), and long (more than $10 \mathrm{~h}$ ) wet spells. The significance is computed as the difference between observed frequency and the expected frequency beyond the seasonal cycle, estimated by 1000 random permutation of the WT sequences by blocks of 3 consecutive days in nonoverlapping 15 days. Black triangles indicate significant anomalies at the two-sided $95 \%$ level.

filtered by the methodology. We have demonstrated that WTs are also consistent with "break versus active" phases of the regional-scale monsoon (Table 2) and that they match reasonably well with the local-scale weather regimes (Pope et al. 2009; Catto et al. 2012) defined from radio soundings at Darwin (Table 1) as well as with the regional-scale WT defined over the Maritime Continent (Moron et al. 2015a) (Table 4). The tracks and locations of cyclonic events are also significantly modulated by the WT occurrence (Fig. A4).
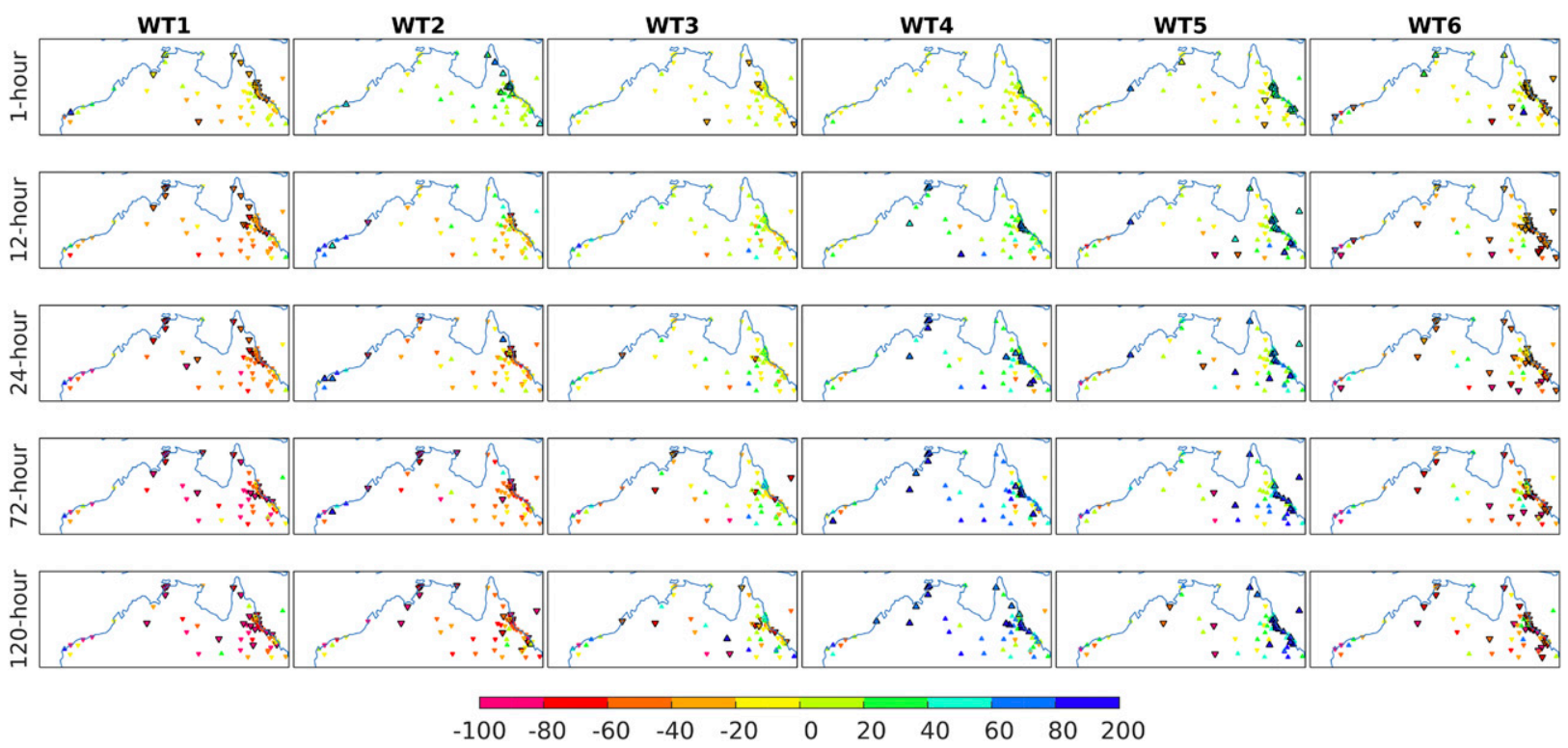

FIG. 14. As in Fig. 13, but for the frequency of the last decile of rainfall amounts for 1-, 12-, 24-, 72-, and 120-h time steps receiving respectively at least $0.2,2.4,4.8,14.4$, and $24 \mathrm{~mm}$. The significance is estimated as in Fig. 11 and significant anomalies at the two-sided $95 \%$ level are shown as black triangles. 
(a) Total rainfall

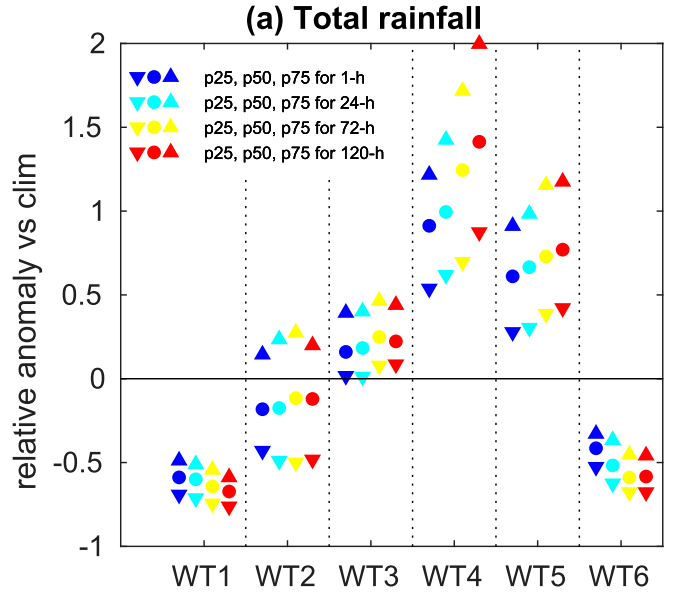

(c) Rainfall intensity during wet hours

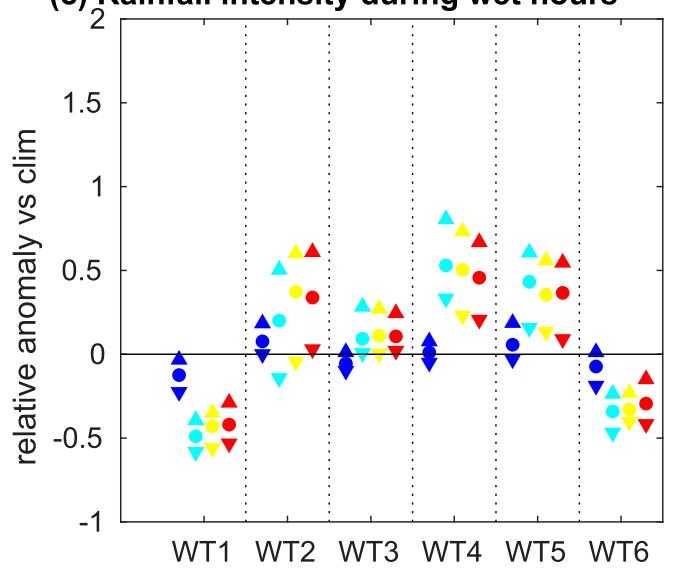

(b) Frequency of wet hours

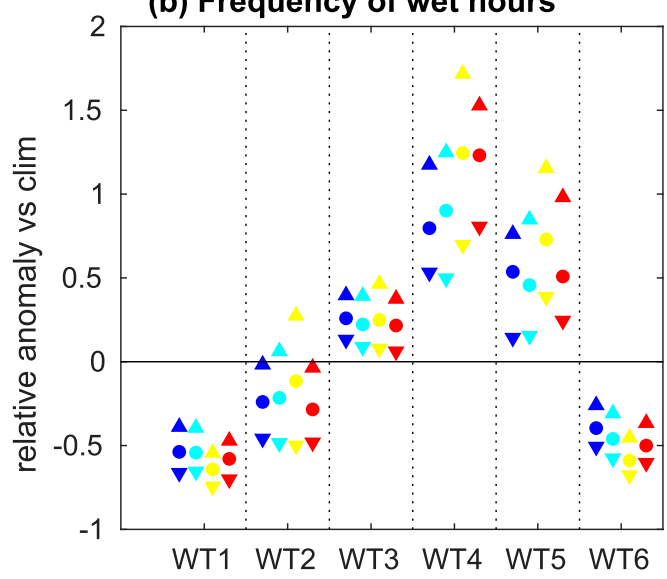

(d) Frequency of wet spells

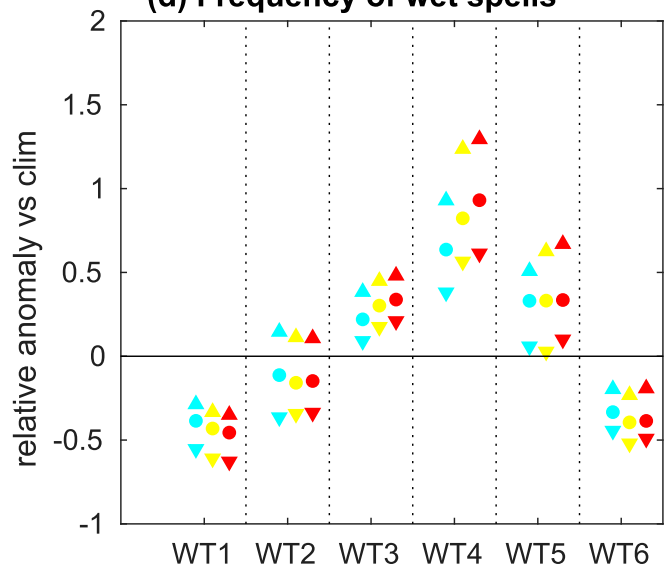

(e) Mean length of wet spells

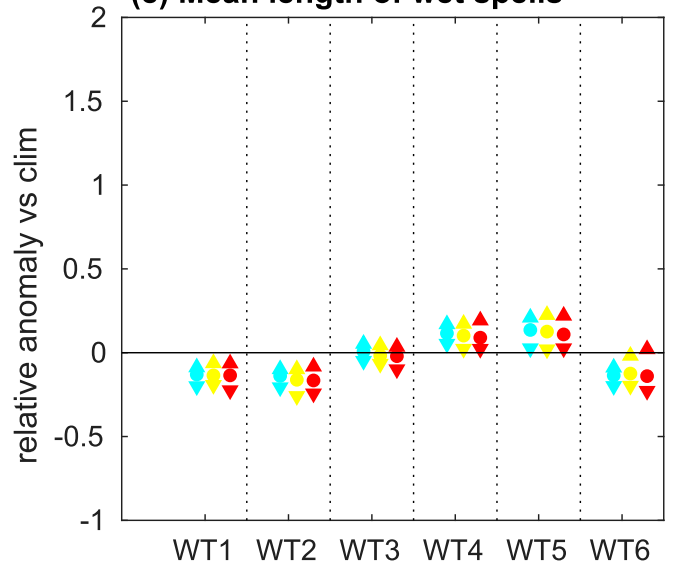

FIG. 15. Quantiles (across the 61 stations) of (a) the relative anomalies of total rainfall, (b) frequency of wet hours, (c) mean intensity of rainfall during wet hours, (d) frequency of wet spells, and (e) mean length of wet spells across the WTs for hourly (dark blue), 24-h (light blue), 72-h (yellow), and 120-h (red) running periods.

In that context, a WT should be interpreted as a simple coarse-grained pattern of the complex interaction of atmospheric motions leading to varying and, always different, instantaneous conditions. Here, WTs appear to combine at least five different time scales and phenomena: (i) the mean annual cycle, exemplified by the contrast between the trade-wind WTs (WT1 and WT6) and the monsoonal WTs (WTs 3-5); (ii) the 
phases of the MJO, illustrated by the transition from one WT to another (Figs. 8 and A5-A7); (iii) the state of ENSO phenomenon (Fig. 7); (iv) more transient and short-lived, but recurrent, phenomena (as low pressure systems northwest of Australia in WT4, Fig. 3d); and (v) the diurnal cycle, mostly through the anomalously positive (negative) occurrence of the transitional WT2 (monsoonal WT3) at 0600 UTC (Fig. 6). The WTs first document the annual evolution of the regional-scale monsoon as well as its break versus active phases. This fingerprint is observed in the mean seasonal cycle (Fig. 3g) and for specific seasons such as 1983/84 and 1987/88 (Fig. 4). From this point of view, WT1 and WT6 are mostly associated with trade-wind regimes before and after the monsoonal season, but also (especially WT6) with the breaks during the rainy season, both setting up dry conditions over tropical Australia (Fig. 9). The transitional premonsoon (or build-up) season around mid- to late November is identified here with WT2, triggering short, scattered, but potentially intense, rainfall. The last three monsoonal WTs 3-5 are typical of the core of the regional-scale monsoon, from midDecember to early March, and are associated with wet conditions (Fig. 9). WT4 and WT5 reflect the active phases of the monsoon with low-level westerlies over the Arafura Sea, the Gulf of Carpentaria, and adjacent tropical Australia, while low-level easterlies are still present over northern Australia in WT3. Beyond the representation of the smooth evolution of the annual cycle, the WT's framework is also relevant to describe the transitions associated with the onset and demise of the regional-scale monsoon; the onset (demise) of the monsoon is mostly associated with a sudden increase (decrease) of WT4 and 5, while WT1 disappears (appears) thereafter (Fig. 5). Overall, the WT framework offers an unified paradigm of the monsoonal circulation. In particular, it suggests that the succession of contrasted WTs (as WTs 1 and 6 versus WTs 4 and 5) may be intrinsic to the monsoonal circulation. From that point of view, the regional-scale breaks, associated with either WT1 or mostly WT6 and dry conditions across tropical Australia, may indeed occur during the core of the rainy season, as in 1987/88 (Fig. 4). This suggests that the amplitude of intraseasonal variability, exemplified by the incursion of WT1 or WT6 during the monsoon, may be as large as the seasonal cycle.

The relative influence of the five time scales described above differs among the WTs. For example, WT3 exemplifies the core of the monsoon season (i.e., the January monthly mean) and also projects strongly onto the MJO phase when the convective pole is close to the eastern Indian Ocean and western Maritime Continent, and also represents the atmospheric pattern that projects the most

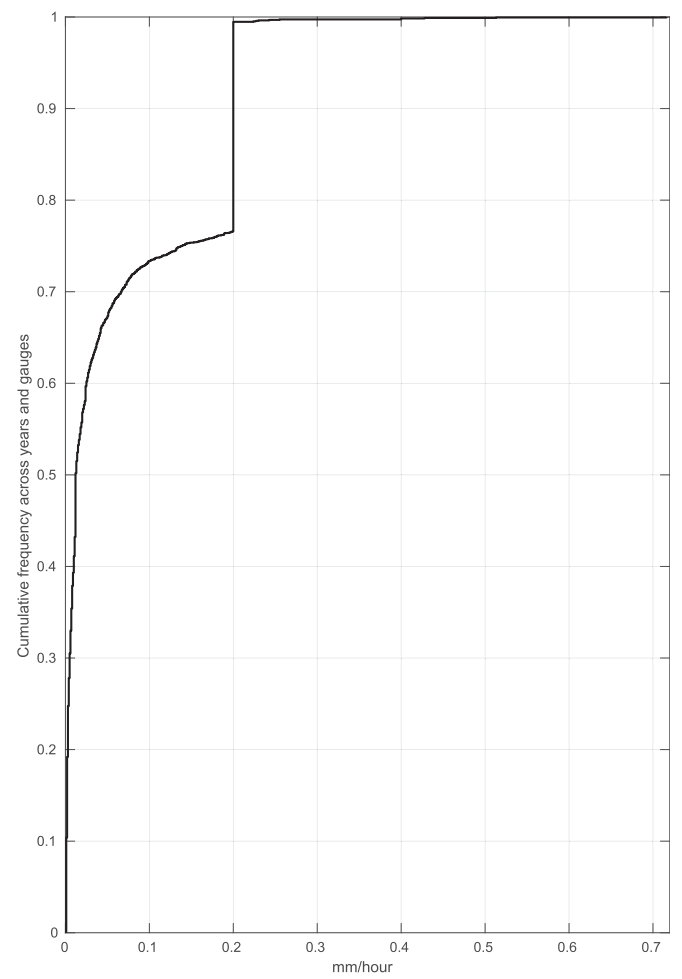

FIG. A1. PDF of the minimum hourly rainfall received for each station and each November-March season. Only available entries are used.

onto the November-March anomalies related to ENSO. In that context, the ENSO signature during La Niña events is clearly illustrated by the mean wind anomalies associated with this WT; that is, a large-scale low-level convergence around the Timor Sea and anomalously strong westerlies over Indonesia. In contrast, WT4 appears mostly associated with transient low pressure peaking over NW Australia, but also with the cyclonic anomalies related to the MJO when the convective pole travels north of Australia across the Maritime Continent.

The sequences of WTs may also be used to "deconstruct" and understand seasonal anomalies (and their subseasonal modulation) related to ENSO or MJO. Regarding ENSO, the WT framework may help to elucidate both the nonlinearities and the subseasonal modulation of the ENSO teleconnection in tropical Australia. While the modulation of WT1 and WT6 is broadly symmetric between El Niño and La Niña events, the modulation of WT3, which is the most sensitive WT to the ENSO phenomenon (Fig. 7d and Table 5), is stronger for La Niña than for El Niño events. This is consistent with the largest impact observed during La Niña events on seasonal rainfall anomalies (McBride and Nicholls 1983; Risbey et al. 2009; King et al. 2014). Regarding the subseasonal modulation, our results provide more insights on the large 

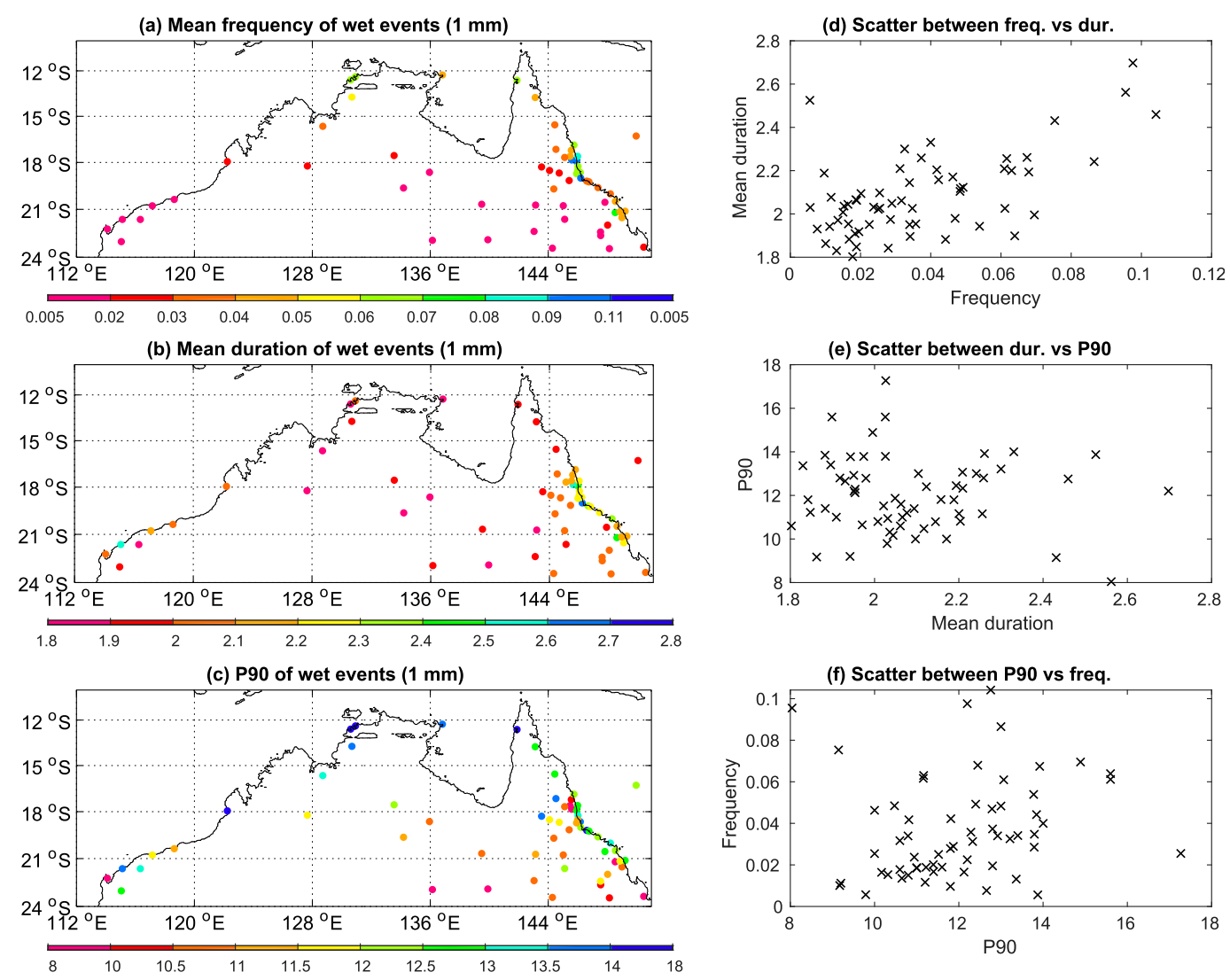

FIG. A2. (a) Relative frequency of hourly time steps receiving at least $1 \mathrm{~mm} \mathrm{~h}^{-1}$. (b) Mean duration in hours of wet spells receiving at least $1 \mathrm{~mm} \mathrm{~h}^{-1}$. (c) 90th percentile of hourly wet spells receiving at least $1 \mathrm{~mm} \mathrm{~h}^{-1}$. (d) Scatterplot of relative frequency in abscissa vs mean duration in ordinate. (e) Scatterplot of mean duration in abscissa vs P90 in ordinate. (f) Scatterplot of P90 in abscissa vs relative frequency in ordinate.

ENSO impact observed in spring (McBride and Nicholls 1983) since both WT1 and WT6 are more (less) prevalent during El Niño (La Niña) events, thereby delaying (hastening) the onset of the austral monsoon, as already noticed across the Maritime Continent (Moron et al. 2009, 2010). Note also that the anomalies of WT2 around late November (Fig. 7c) suggest that the transition season is more active in La Niña versus El Niño years. During the core of the austral monsoon, WT4 and WT5, which lead to the largest positive rainfall anomalies respectively over most of tropical and northeast Australia, are almost never impacted by ENSO state, thereby weakening somewhat the impact of ENSO events on total seasonal rainfall.

The modulation of local-scale rainfall by the WTs is of interest. First of all, the strongest modulation is observed for the frequency of wet hours, as seen in previous studies (Pui et al. 2012). This suggests that the triggering of wet conditions is related to relatively large-scale systems revealed by the WTs. The modulation of duration and intensity of wet events is however weaker. Generally, the trade-wind WTs (WT1 and WT6) favor short wet spells while the monsoonal WTs (especially WT5) favor longer wet spells. Regarding the intensity, an interesting result is the distinction between hourly events and those aggregated over more than 6-12 h. At the hourly time scale, the WTs leading to the highest frequency of rainfall extremes are WT2 and WT5. The former WT is in fact related to weak winds, thus promoting local-scale convection as soon as enough moisture is available to trigger the formation of deep clouds. Drosdowsky (1996) indicated that premonsoon rainfall events around Darwin result mainly from convective activity in the form of both large-scale organized systems and randomly scattered thunderstorms. We can hypothesize that WT2 mostly generates the second type of system. Note that this WT is also associated with more frequent wet hours in the interior of southern Queensland. Breezes may also be favored during this WT, especially over the York Peninsula. This result is similar to that observed over the Maritime Continent during a quiescent WT, that is, when synoptic winds are weak and favor small-scale convection over mountains and specific parts of islands, while rainfall is anomalously low across 
(a) WT1

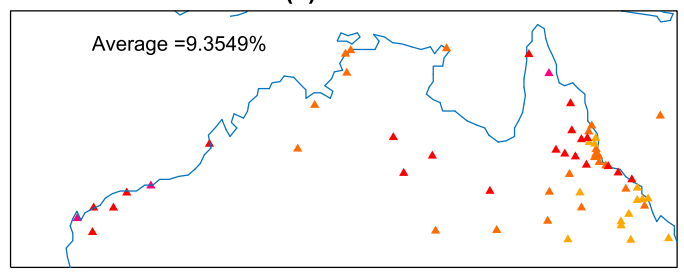

(c) WT3

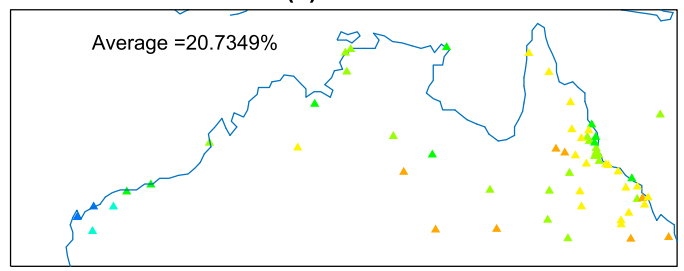

(e) WT5

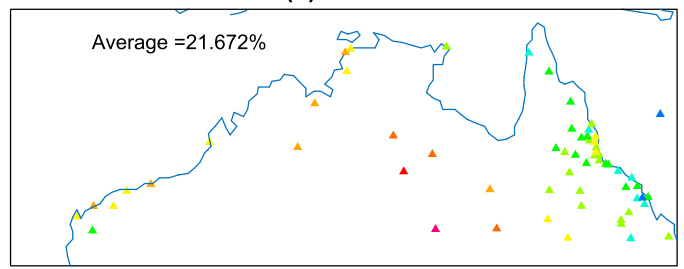

(b) WT2

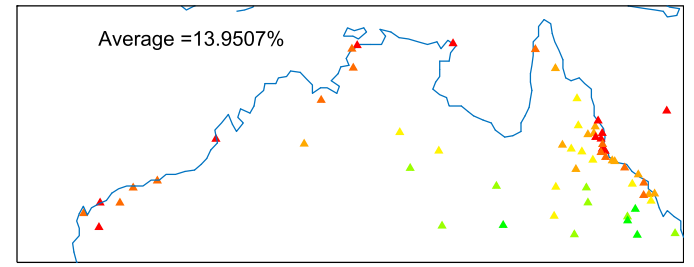

(d) WT4

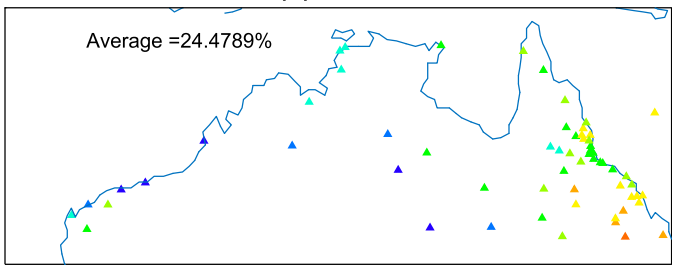

(f) WT6

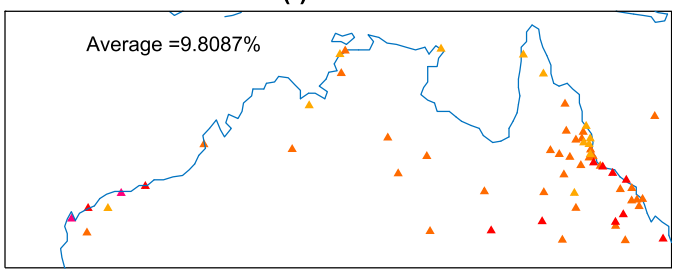

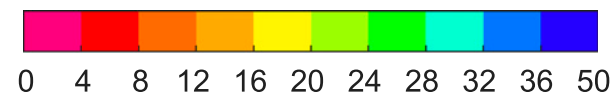

FIG. A3. Contribution of each WT to the total rainfall in percent.

inner seas (Moron et al. 2015a). Beyond the case of WT2, the overall weak modulation of the intensity of wet hours is also consistent with the weak spatial contrasts of the 90th percentile (Table 1). This means that hourly extremes are mostly driven by local-scale thermodynamical processes, whose intensity does not vary much in space. As the temporal aggregation grows, the modulation of intensity tends to follow what is expected from the wet day seasonality, which is less extreme rainfall for trade-wind WTs and more for monsoonal WTs.

An interesting extension of this work would be to use the WT framework to explore the ability of global and regional climate models to simulate both the observed frequency of WTs and their impact on precipitation frequency, duration and intensity. Including simulations from the new generation of convection-permitting models (CPMs) (e.g., Kendon et al.

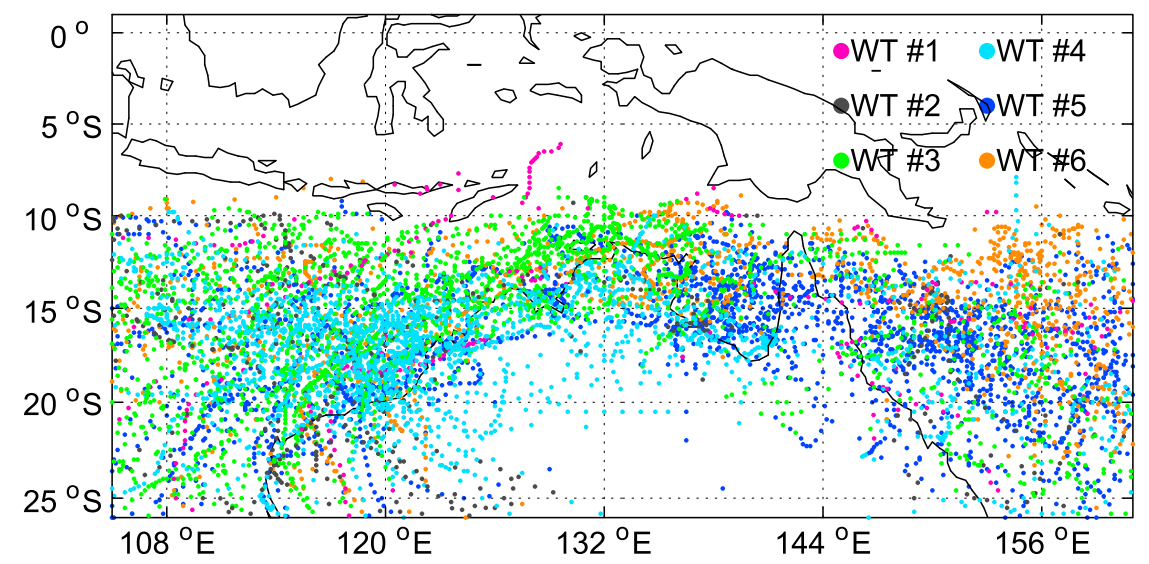

FIG. A4. Location of cyclonic centers during the 6 weather types. 

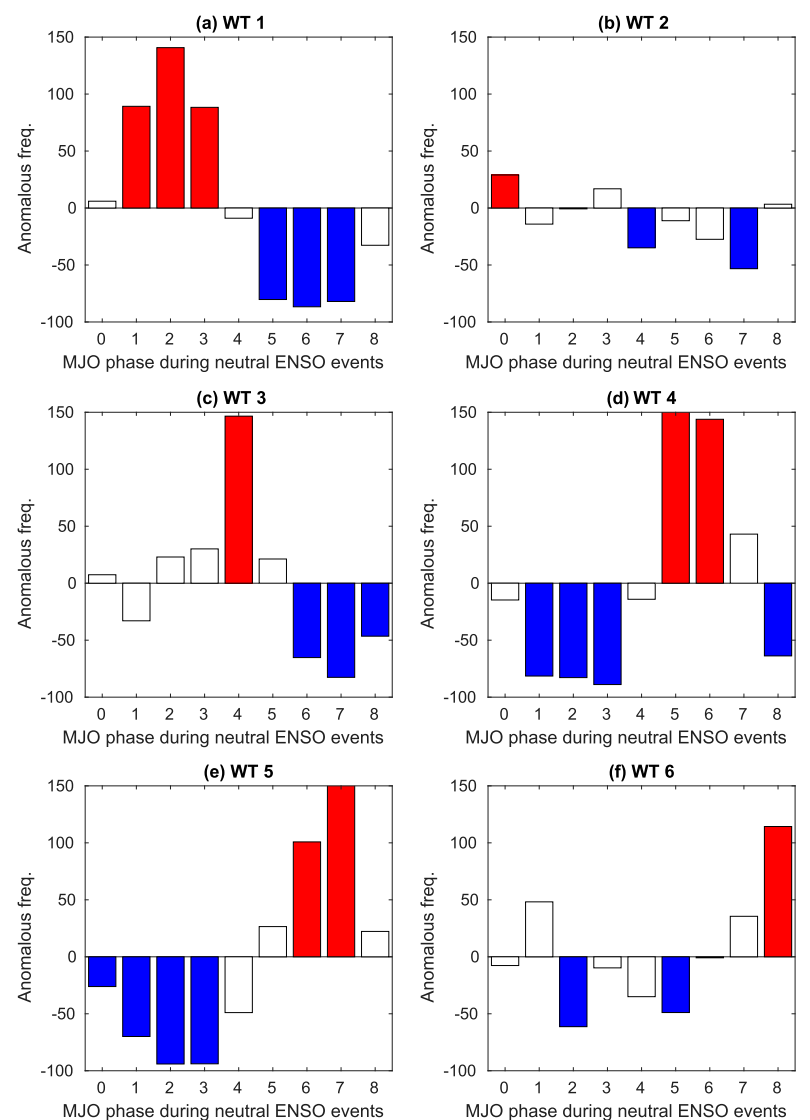

FIG. A5. Modulation of the occurrence of WT due to the MJO (expressed as the anomalies in percentage vs the expected frequency) for the neutral (vs warm and cold ENSO events) NDJFM seasons. The red (blue) bars show significant anomalies at the twosided $95 \%$ level according to 1000 random permutation of the seasonal sequences of each WT. The eight phases of the MJO (+ phase 0 when the MJO is weak) are defined from Wheeler and Hendon (2004).

2017) would enable the analysis of mechanisms contributing to hourly extreme rainfall in more detail throughout the atmospheric column and interactions with the land surface and how these and rainfall characteristics might change in tropical north Australia with global warming.

Acknowledgments. We would like to warmly thank Mick Pope and Alain Protat for providing the updated time series of their weather regimes computed from Darwin radiosoundings and Harry Hendon for providing the time series of the spatially-averaged Australian rainfall north of $2^{\circ} \mathrm{S}$. The ERA-Interim and ERA5 data have been provided by ECMWF. We thank two anonymous reviewers for their suggestions which have significantly improved the paper. We thank also John McBride for his extremely detailed and constructive
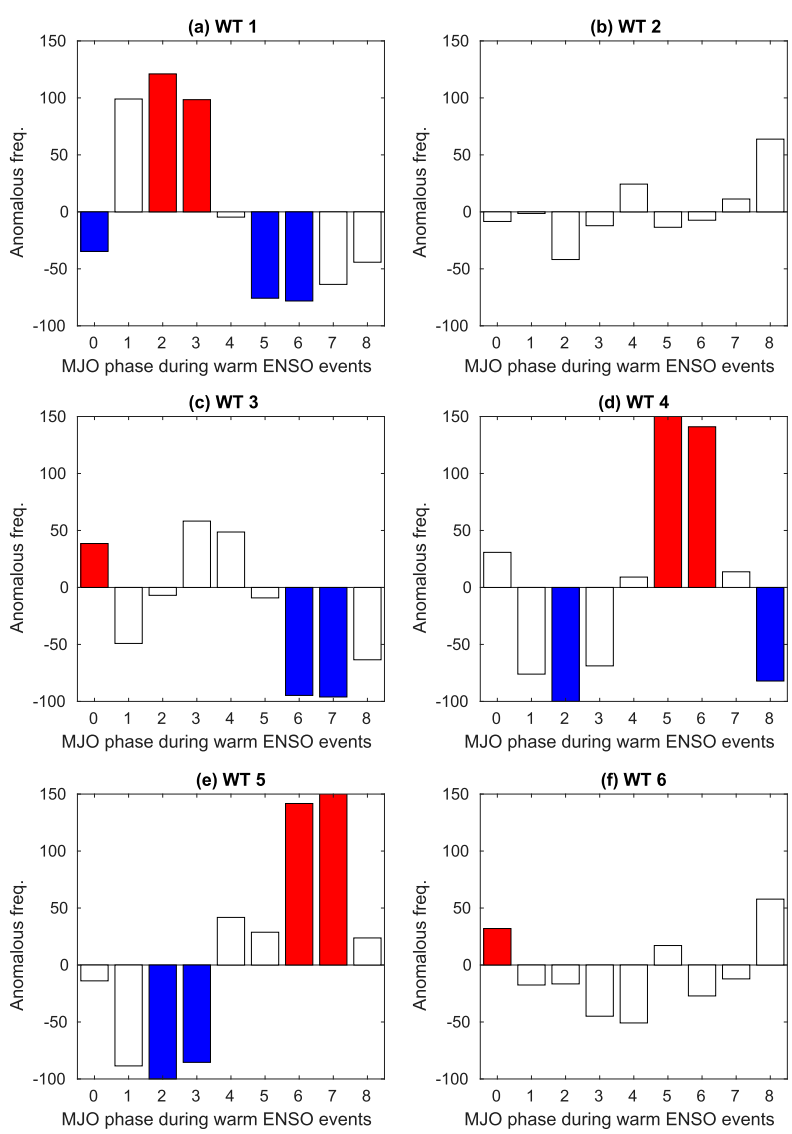

FIG. A6. Modulation of the occurrence of WT due to the MJO (expressed as the anomalies in percentage vs the expected frequency) for the warm NDJFM seasons (1982/83, 1986/87, 1991/92, 1994/95, 1997/98, 2002/03, 2009/10, 2015/16). The red (blue) bars show significant anomalies at the two-sided $95 \%$ level according to 1000 random permutation of the seasonal sequences of each WT. The eight phases of the MJO ( + phase 0 when the MJO is weak) are defined from Wheeler and Hendon (2004).

comments. HJF would like to acknowledge financial support from the European Research Council project INTENSE (Grant ERC-2013-CoG-617329) and from the Wolfson Foundation and the Royal Society as a Royal Society Wolfson Research Merit Award (WM140025) holder.

\section{APPENDIX}

\section{Additional Figures}

The appendix contains Figs. A1-A8. Figure A1 shows the CDF of the minimum of recorded rainfall $>0 \mathrm{~mm} \mathrm{~h}^{-1}$ across the 35 November-March seasons and the 61 stations. More than $99 \%$ of the values are $\leq$ $0.2 \mathrm{~mm} \mathrm{~h}^{-1}$. Figure A2 shows the same characteristics 

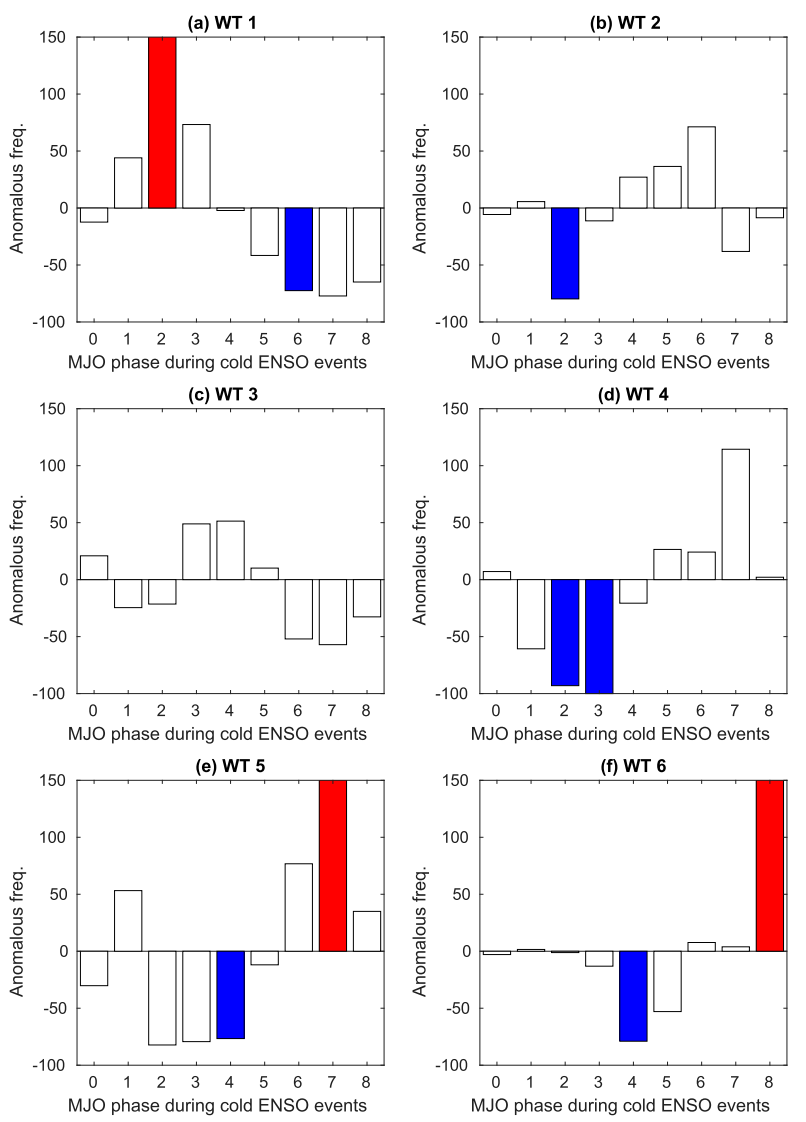

FIG. A7. Modulation of the occurrence of WT due to the MJO (expressed as the anomalies in percentage vs the expected frequency) for the cold NDJFM seasons (1984/85, 1988/89, 1995/96, 1998/99, 1999/2000, 2007/08, 2008/09, 2010/11). The red (blue) bars show significant anomalies at the two-sided $95 \%$ level according to 1000 random permutation of the seasonal sequences of each WT. The eight phases of the MJO (+ phase 0 when the MJO is weak) are defined from Wheeler and Hendon (2004).

as Fig. 2 using a threshold of $1 \mathrm{~mm} \mathrm{~h}^{-1}$ instead of 0.2 $\mathrm{mm} \mathrm{h}{ }^{-1}$. Figure A3 shows the contribution of the WTs to the total amount of rainfall received in NovemberMarch. Figure A4 shows the location of the cyclonic centers for each WT. Figures A5-A7 show the same information as Fig. 8 except that the November-
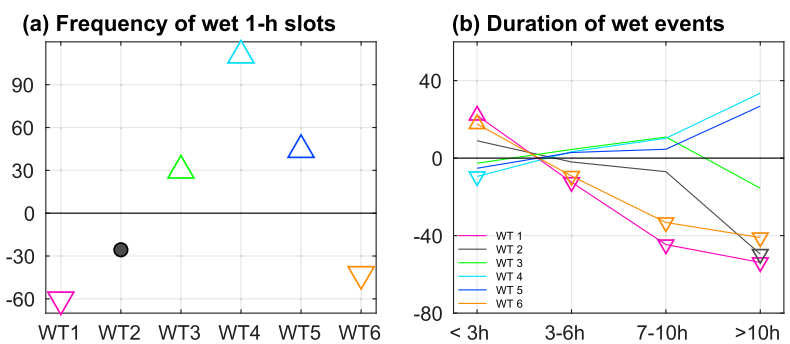

FIG. A8. As in Fig. 11, but for a threshold of $1 \mathrm{~mm} \mathrm{~h}^{-1}$.
March seasons are discretized into neutral, warm, and cold ENSO years respectively. Even if the significance varies, the occurrence of WTs is modulated in a similar way by the phases of the MJO. Lastly, Fig. A8 is similar to Fig. 11 using a threshold of $1 \mathrm{~mm} \mathrm{~h}^{-1}$ instead of $0.2 \mathrm{~mm} \mathrm{~h}^{-1}$.

\section{REFERENCES}

Agel, L., M. Barlow, J.-H. Qian, F. Colby, E. Douglas, and T. Eichler, 2015: Climatology of daily precipitation and extreme precipitation events in the northeast United States. J. Hydrometeor., 16, 2537-2557, https://doi.org/10.1175/JHM-D-14-0147.1.

Ali, H., and V. Mishra, 2018: Contribution of dynamic and thermodynamic scaling on sub-daily precipitation extremes in India. Geophys. Res. Lett., 45, 2352-2361, https://doi.org/10.1002/2018GL077065.

Bao, J., S. C. Sherwood, L. V. Alexander, and J. P. Evans, 2017: Future increases in extreme precipitation exceed observed scaling rates. Nat. Climate Change, 7, 128-132, https://doi.org/ 10.1038/nclimate3201.

Barbero, R., S. Westra, G. Lenderink, and H. J. Fowler, 2018: Temperature-extreme precipitation scaling: A two-way causality? Int. J. Climatol., 38, e1274-e1279, https://doi.org/10.1002/joc.5370.

, J. T. Abatzoglou, and H. J. Fowler, 2019: Contribution of large-scale midlatitude disturbances to hourly precipitation extremes in the United States. Climate Dyn., 52, 197-208, https://doi.org/10.1007/s00382-018-4123-5.

Catto, J., C. Jakob, and N. Nicholls, 2012: The influence of changes in synoptic regimes on north Australian wet season rainfall trends. J. Geophys. Res., 117, D10102, https://doi.org/10.1029/ 2012JD017472.

Christiansen, B., 2007: Atmospheric circulation regimes: Can cluster analysis provide the number? J. Climate, 20, 22292250, https://doi.org/10.1175/JCLI4107.1.

Clark, S., M. Reeder, and C. Jakob, 2018: Rainfall regimes over Northwestern Australia. Quart. J. Roy. Meteor. Soc., 144, 458467, https://doi.org/10.1002/qj.3217.

Dai, A., and J. Slingo, 1999: Diurnal and semidiurnal variations in global surface wind and divergence fields. J. Geophys. Res. Atmos., 104, 31109-31 125, https://doi.org/10.1029/ 1999JD900927.

— R. M. Rasmussen, C. Liu, K. Ikeda, and A. F. Prein, 2017: A new mechanism for warm-season precipitation response to global warming based on convection-permitting simulations. Climate Dyn., https://doi.org/10.1007/s00382-017-3787-6.

Drosdowsky, W., 1996: Variability of the Australian summer monsoon at Darwin: 1957-1992. J. Climate, 9, 85-96, https://doi.org/ 10.1175/1520-0442(1996)009<0085:VOTASM > 2.0.CO;2.

Dunkerley, D., 2019: How does sub-hourly rainfall intermittency bias the climatology of hourly and daily rainfalls? Examples from arid and wet Tropical Australia. Int. J. Climatol., 39, 2412-2421, https://doi.org/10.1002/joc.5961.

Ghil, M., and A. Robertson, 2002: "Waves" vs. "particles" in the atmosphere's phase space: A pathway to long-range forecasting? Proc. Natl. Acad. Sci. USA, 99, 2493-2500, https:// doi.org/10.1073/pnas.012580899.

Guerreiro, S. B., H. Fowler, R. Barbero, S. Westra, G. Lenderink, S. Blenkinsop, E. Lewis, and X.-F. Li, 2018: Detection of continental-scale intensification of hourly rainfall extremes. Nat. Climate Change, 8, 803-807, https://doi.org/10.1038/s41558018-0245-3. 
Hardwick Jones, R., S. Westra, and A. Sharma, 2010: Observed relationships between extreme sub-daily precipitation, surface temperature and relative humidity. Geophys. Res. Lett., 37, L22805, https://doi.org/10.1029/2010GL045081.

Hendon, H. H., and B. Liebmann, 1990: A composite study of onset of the Australian summer monsoon. J. Atmos. Sci., 47, 2227-2240, https://doi.org/10.1175/1520-0469(1990) 047<2227:ACSOOO > 2.0.CO;2.

Huffman, G. J., R. Adler, M. Morrissey, D. Boivin, S. Curtis, R. Joyce, B. McGavock, and J. Susskind, 2001: Global precipitation at one-degree daily resolution from multisatellite observations. J. Hydrometeor., 2, 36-50, https://doi.org/ 10.1175/1525-7541(2001)002<0036:GPAODD>2.0.CO;2.

— , R. J. Adler, and D. T. Boivin, 2009: Improving the global precipitation record: GPCP version 2.1. Geophys. Res. Lett., 36, L17808, https://doi.org/10.1029/2009g1040000.

Hung, C.-W., and M. Yanai, 2004: Factors contributing to the onset of the Australian summer monsoon. Quart. J. Roy. Meteor. Soc., 130, 739-758, https://doi.org/10.1256/qj.02.191.

Jones, D., W. Wang, and R. Fawcett, 2009: High-quality spatial climate data-sets for Australia. Aust. Meteor. Oceanogr. J., 58, 233-248, https://doi.org/10.22499/2.5804.003.

Kendon, E. J., and Coauthors, 2017: Do convection-permitting regional climate models improve projections of future precipitation change? Bull. Amer. Meteor. Soc., 98, 79-93, https:// doi.org/10.1175/BAMS-D-15-0004.1.

King, A., N. P. Klingaman, L. V. Alexander, M. G. Donat, N. C. Jourdain, and P. Maher, 2014: Extreme rainfall variability in Australia: Patterns, drivers and predictability. J. Climate, 27, 6035-6050, https://doi.org/10.1175/JCLI-D-13-00715.1.

Lenderink, G., R. Barbero, J. Loriaux, and H. Fowler, 2017: Super-Clausius-Clapeyron scaling of extreme hourly convective precipitation and its relation to large-scale atmospheric conditions. J. Climate, 30, 6037-6052, https://doi.org/10.1175/ JCLI-D-16-0808.1.

Lochbihler, K., G. Lenderink, and A. P. Siebesma, 2017: The spatial extent of rainfall events and its relation to precipitation scaling. Geophys. Res. Lett., 44, 8629-8636, https://doi.org/ 10.1002/2017GL074857.

Loriaux, J. M., G. Lenderink, and A. Pier Siebesma, 2017: Largescale controls on extreme precipitation. J. Climate, 30, 955968, https://doi.org/10.1175/JCLI-D-16-0381.1.

Luo, Y., M. Wu, F. Ren, J. Li, and W. K. Wong, 2016: Synoptic situations of extreme hourly precipitation over china. J. Climate, 29, 8703-8719, https://doi.org/10.1175/JCLI-D16-0057.1.

May, P., J. Mather, G. Vaughan, C. Jakob, G. McFarquhar, K. Brown, and G. Mace, 2008: The Tropical Warm Pool International Cloud Experiment. Bull. Amer. Meteor. Soc., 89, 629-645, https://doi.org/10.1175/BAMS-89-5-629.

McBride, J. L., 1987: The Australian summer monsoon. Monsoon Meteorology, C. Chang and T. Krishnamurti, Eds., Oxford University Press, 203-231.

__ , and N. Nicholls, 1983: Seasonal relationships between Australian rainfall and the Southern Oscillation. Mon. Wea. Rev., 111, 1998-2004, https://doi.org/10.1175/1520-0493(1983) $111<1998$ :SRBARA $>2.0 . \mathrm{CO} ; 2$.

Michelangeli, P.-A., R. Vautard, and B. Legras, 1995: Weather regimes: Recurrence and quasi stationarity. J. Atmos. Sci., 52, 1237-1256, https://doi.org/10.1175/1520-0469(1995)052<1237: WRRAQS $>2.0$.CO;2.

Moron, V., A. W. Robertson, M. N. Ward, and O. Ndiaye, 2008: Weather types and rainfall over Senegal. Part I: Observa- tional analysis. J. Climate, 21, 266-287, https://doi.org/10.1175/ 2007JCLI1601.1.

,$- \ldots$, and R. Boer, 2009: Spatial coherence and seasonal predictability of monsoon onset over Indonesia. J. Climate, 22 , 840-850, https://doi.org/10.1175/2008JCLI2435.1.

$\longrightarrow,-$, and J. Qian, 2010: Local versus regional-scale characteristics of monsoon onset and post-onset rainfall over Indonesia. Climate Dyn., 34, 281-299, https://doi.org/10.1007/ s00382-009-0547-2.

$\longrightarrow,-$ J.-H. Qian, and M. Ghil, 2015a: Weather types across the Maritime Continent: From the diurnal cycle to interannual variations. Front. Environ. Sci., 2, 65, https://doi.org/10.3389/fenvs.2014.00065.

_- and Coauthors, 2015b: Ethnographic context and spatial coherence of climate indicators for farming communities-A multi-regional comparative assessment. Climate Risk Manage., 8, 28-46, https://doi.org/10.1016/j.crm.2015.03.001.

— I. Gouirand, and M. Taylor, 2016: Weather types across the Caribbean basin and their relationship with rainfall and sea surface temperature. Climate Dyn., 47, 601-621, https:// doi.org/10.1007/s00382-015-2858-9.

Narsey, S., M. J. Reeder, D. Ackerley, and C. Jakob, 2017: A midlatitude influence on Australian monsoon bursts. J. Climate, 30, 5377-5393, https://doi.org/10.1175/JCLI-D-16-0686.1.

Pfahl, S., P. A. O'Gorman, and E. M. Fischer, 2017: Understanding the regional pattern of projected future changes in extreme precipitation. Nat. Climate Change, 7, 423-427, https://doi.org/ 10.1038/nclimate3287.

Pohl, B., P. Camberlin, and P. Roucou, 2005: Typology of pentad circulation anomalies over the eastern Africa-western Indian Ocean region and their relationship with rainfall. Climate Res., 29, 111-127, https://doi.org/10.3354/cr029111.

Pope, M., C. Jakob, and M. Reeder, 2009: Regimes of the north Australian wet season. J. Climate, 22, 6699-6715, https:// doi.org/10.1175/2009JCLI3057.1.

Pui, A., A. Sharma, A. Santoso, and S. Westra, 2012: Impact of the El Niño-Southern Oscillation, Indian Ocean dipole, and southern annular mode on daily to subdaily rainfall characteristics in East Australia. Mon. Wea. Rev., 140, 1665-1682, https://doi.org/10.1175/MWR-D-11-00238.1.

Qian, J.-H., A. W. Robertson, and V. Moron, 2010: Interactions among ENSO, the monsoon, and diurnal cycle in rainfall variability over Java, Indonesia. J. Atmos. Sci., 67, 3509-3524, https://doi.org/10.1175/2010JAS3348.1.

$\longrightarrow, \ldots$, and -2013 : Diurnal cycle in different weather regimes and rainfall variability over Borneo associated with ENSO. J. Climate, 26, 1772-1790, https://doi.org/10.1175/JCLI-D-12-00178.1.

Ricciardulli, L., and P. Sardeshmukh, 2002: Local time- and space scales of organized tropical deep convection. J. Climate, 15, 2775-2790, https:// doi.org/10.1175/1520-0442(2002)015<2775:LTASSO>2.0.CO;2.

Risbey, J. S., M. J. Pook, P. McIntosh, M. C. Wheeler, and H. H. Hendon, 2009: On the remote drivers of rainfall variability in Australia. Mon. Wea. Rev., 137, 3233-3253, https://doi.org/ 10.1175/2009MWR2861.1.

Roller, C. D., J.-H. Qian, L. Agel, M. Barlow, and V. Moron, 2016: Winter weather regimes in the northeast United States. J. Climate, 29, 2963-2980, https://doi.org/10.1175/JCLI-D-15-0274.1.

Slingo, J., P. Inness, R. Neale, S. Woolnough, and G.-Y. Yang, 2003: Scale interactions on diurnal to seasonal time scales and their relevance to model systematic errors. Ann. Geophys., 46, 139-155, https://doi.org/10.4401/ag-3383.

Suppiah, R., 1992: The Australian summer monsoon: A review. Prog. Phys. Geogr., 16, 283-318, https://doi.org/10.1177/ 030913339201600302. 
Trenberth, K., Y. Zhang, and M. Gehne, 2017: Intermittency in precipitation: Duration, frequency, intensity and amounts using hourly data. J. Hydrometeor., 18, 1393-1412, https:// doi.org/10.1175/JHM-D-16-0263.1.

Troup, A., 1961: Variations in upper tropospheric flow associated with the onset of the Australian summer season. Indian J. Meteor. Geophys., 12, 217-230.

Utsumi, N., H. Kim, S. Kanae, and T. Oki, 2017: Relative contributions of weather systems to mean and extreme global precipitation. J. Geophys. Res. Atmos., 122, 152-167, https:// doi.org/10.1002/2016jd025222.

Wasko, C., A. Sharma, and F. Johnson, 2015: Does storm duration modulate the extreme precipitation-temperature scaling relationship? Geophys. Res. Lett., 42, 8783-8790, https://doi.org/ 10.1002/2015GL066274.
Westra, S., and Coauthors, 2014: Future changes to the intensity and frequency of short-duration extreme rainfall. Rev. Geophys., 52, 522-555, https://doi.org/10.1002/2014RG000464.

Wheeler, M. C., and H. H. Hendon, 2004: An all-season realtime multivariate MJO index: Development of an index for monitoring and prediction. Mon. Wea. Rev., 132, 1917-1932, https:// doi.org/10.1175/1520-0493(2004)132<1917:AARMMI>2.0.CO;2. , and J. L. McBride, 2005: Australian-Indonesian monsoon. Intraseasonal Variability of the Atmosphere-Ocean Climate System, W. Lau and D. Walliser, Eds., Springer, 125-173.

Xie, S., T. Hume, C. Jakob, S. A. Klein, R. B. McCoy, and M. Zhang, 2010: Observed large-scale structure and diabatic heating and drying profiles during TWP-ICE. J. Climate, 23, 57-79, https:// doi.org/10.1175/2009JCLI3071.1. 